\title{
EPISTEMIC INJUSTICE
}

\author{
BY \\ HANNAH SIMPSON
}

\begin{abstract}
A thesis
submitted to the Victoria University of Wellington in fulfilment of the requirements for the degree of Master of Arts
\end{abstract}

Victoria University of Wellington

2019 


\begin{abstract}
"Epistemic injustice" is a fairly new concept in philosophy, which, loosely speaking, describes a kind of injustice that occurs at the intersection of structures of the social world and knowledge. While the concept was first put forward in the 1990's, the most significant publication on the topic is Miranda Fricker's book Epistemic Injustice: Power and the Ethics of Knowing, which was published in 2007. ${ }^{1}$ Since then, there has been something of an explosion of literature on the topic of epistemic injustice. ${ }^{2}$ However, the concept of epistemic injustice is one that is poorly understood.

While Epistemic Injustice offers extensive analysis of some aspects of epistemic injustice, it does a poor job of explaining, overall, what epistemic injustice actually is, limiting most of that explanation to a small section in the introduction of the book. The way that epistemic injustice is presented in this section is highly ambiguous, with key terms being loosely defined (if at all), and the necessary and sufficient conditions of something being an epistemic injustice are left unclear. This remains unresolved in the literature beyond Fricker's account: while there has been some progression in how we think about epistemic injustice beyond what Fricker's work provides us with, there has been a general failure to adequately recognize and address the ambiguities of the Frickerian account of epistemic injustice.
\end{abstract}

In this thesis, I aim to show that, despite superficial impressions to the contrary, the Frickerian account is fundamentally ambiguous and incomplete. Moreover, later attempts to address these issues by subsequent theorists have failed. This project, however, is not in vain. I conclude by proposing a new account of epistemic injustice that overcomes these problems with the Frickerian account, offering a way of understanding epistemic injustice that is both philosophically satisfying and practically useful.

\footnotetext{
${ }^{1}$ Epistemic Injustice has been cited over 2600 times as of 2019 (according to Google Scholar). All other works on epistemic injustice have citation numbers in the hundreds or below (as of 2019, according to Google Scholar).

${ }^{2}$ Including, but not limited to, over 300 papers in the "Epistemic Injustice" category on PhilPapers as of 2019; and the publication of The Routledge Handbook of Epistemic Injustice (2017).
} 


\section{Contents}

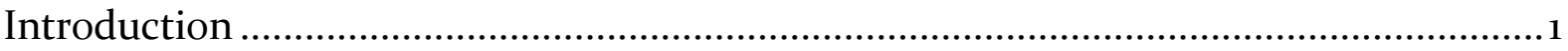

Chapter One: What is Epistemic Injustice?........................................................ 4

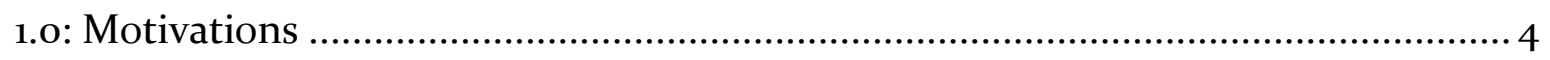

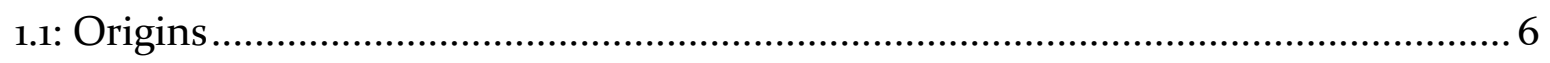

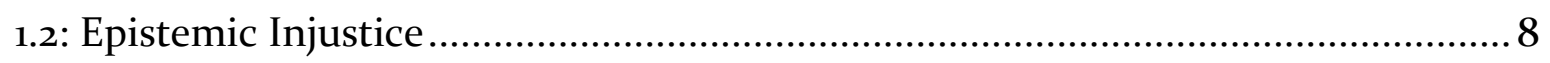

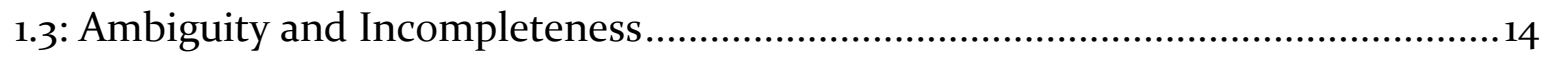

1.4: Developments to the Frickerian Account........................................................19

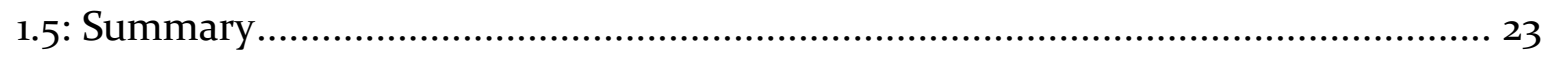

Chapter Two: Moving Past the Frickerian Account ..................................................... 24

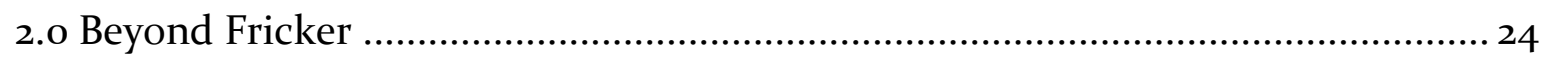

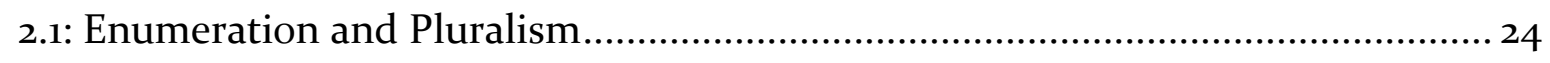

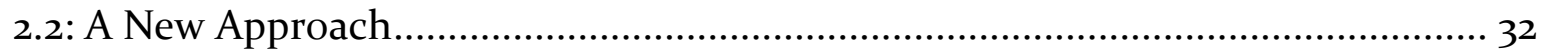

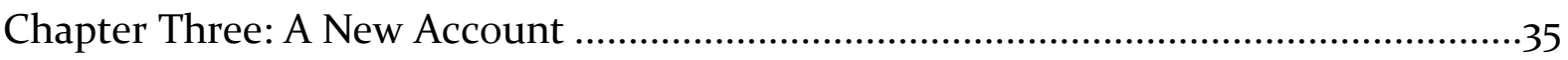

3.0: Revisiting Key Concepts..............................................................................35

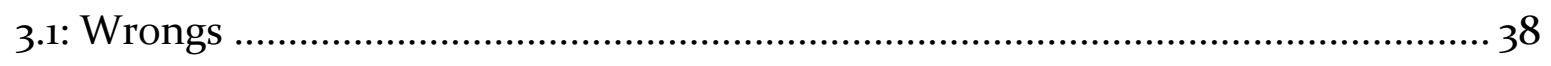

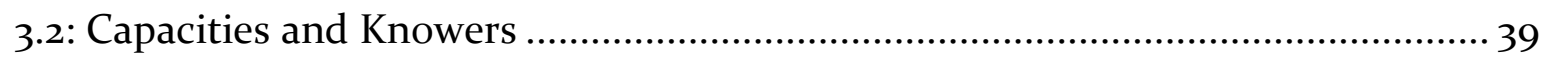

3.3: Distinctiveness and Discrimination ......................................................... 42

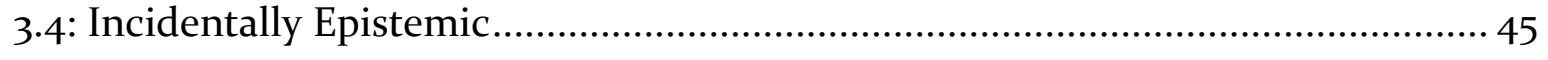

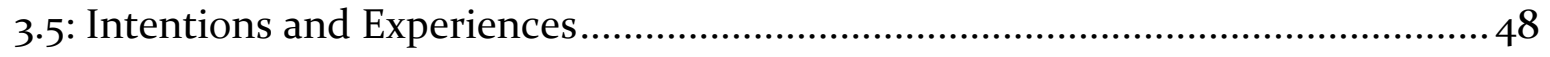

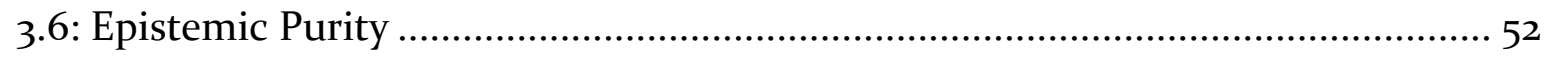

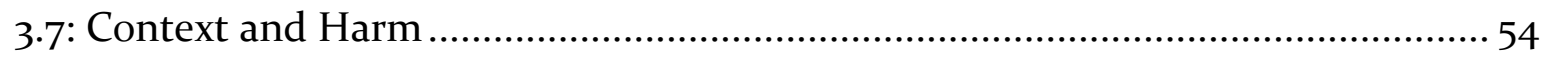

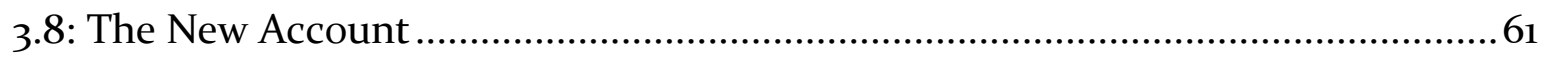

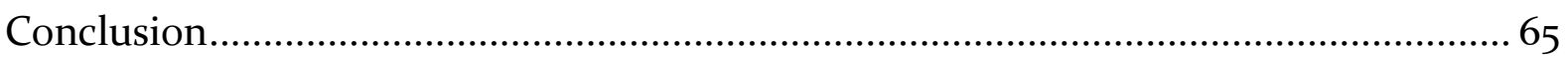

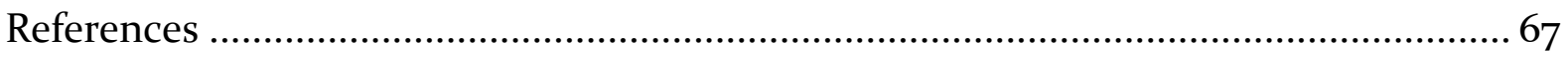




\section{Introduction}

"Epistemic injustice" is a fairly new concept in philosophy, which, loosely speaking, describes a kind of injustice that occurs at the intersection of structures of the social world, and knowledge. While the concept was first put forward in the 1990's, the most significant publication on the topic is Miranda Fricker's book Epistemic Injustice: Power and the Ethics of Knowing, which was published in 2007. Since then, there has been something of an explosion of literature on the topic of epistemic injustice. ${ }^{3}$ However, the concept of epistemic injustice is one that is poorly understood.

While Epistemic Injustice offers extensive analysis of some aspects of epistemic injustice, it does a poor job of explaining, overall, what epistemic injustice actually is, limiting most of that explanation to a small section in the introduction of the book. The way that epistemic injustice is presented in this section is highly ambiguous, with key terms being loosely, if at all defined, and the necessary and sufficient conditions of something being an epistemic injustice being left unclear. This is left unresolved in the literature beyond Fricker's account: while there has been some progression in how we think about epistemic injustice beyond what I will call the "Frickerian account", there has been a general failure to satisfactorily recognize and address the ambiguities of the Frickerian account.

In this thesis, I aim to show that, despite superficial impressions to the contrary, the Frickerian account is fundamentally ambiguous and incomplete. Moreover, later attempts to address these issues by subsequent theorists have failed. This project, however, is not in vain. I conclude by proposing a new account of epistemic injustice that overcomes these problems with the Frickerian account, offering a way of understanding epistemic injustice that is both philosophically satisfying and practically useful.

\footnotetext{
${ }^{3}$ Epistemic Injustice has been cited over 2600 times as of 2019 (according to Google Scholar). All other works on epistemic injustice have citation numbers in the hundreds or below (as of 2019, according to Google Scholar). This "explosion of literature" consists of, but is not limited to, over 300 papers in the "Epistemic Injustice" category on PhilPapers as of 2019; and the publication of The Routledge Handbook of Epistemic Injustice (2017).
} 
In Chapter One, I focus on the Frickerian account of epistemic injustice. In section 1.o, I motivate the central issue of this thesis, discussing why having a clear understanding of the concept of epistemic injustice is desirable. In 1.1, I trace the origins of the concept of epistemic injustice, including papers published on the topic prior to Epistemic Injustice. In 1.2, I give an overview of Epistemic Injustice, focussing on the explanations given of the two central kinds of epistemic injustice-testimonial injustice, and hermeneutical injustice-that Fricker presents. In 1.3, I focus on the introductory passage of Epistemic Injustice, highlighting how it offers an ambiguous and incomplete account of the concept of epistemic injustice overall. In 1.4, I discuss developments that have been made to the Frickerian account by Fricker herself, and show how they in some ways clarify, and in other ways add further questions to, how we should be understanding epistemic injustice. In 1.5, I summarize the chapter, and conclude that the Frickerian account gives us a poor understanding of the concept of epistemic injustice, leaving us without an understanding of the key concepts behind it, or the necessary and sufficient conditions of something being an epistemic injustice.

In Chapter Two, I focus on moving past the Frickerian account of epistemic injustice. In section 2.o I give a brief overview of what the literature on defining epistemic injustice beyond Fricker's work looks like. In 2.1 I discuss two methods of progressing the literature on defining epistemic injustice past the Frickerian account, which I call "the enumerative method" and "the pluralist method". I highlight how neither method solves the ambiguity and incompleteness problems with the Frickerian account, and how both come with their own new problems. In 2.2, I discuss the need for a new account of epistemic injustice that overcomes the problems with the Frickerian account while avoiding the pitfalls of the enumerative method and the pluralist method, and discuss how such an account should be formed, with emphasis on how we should work on forming an account utilizing clarified forms of the key concepts in the Frickerian account.

In Chapter Three, I work on building that new account of epistemic injustice. In section 3.0, I revisit and summarize the key concepts of the Frickerian account, discussing exactly what we need to clarify about each of these concepts. Throughout the rest of the chapter, I work on clarifying each of these concepts, discussing if and how each should 
be understood and utilized, and introducing new key concepts where needed. In 3.1 I focus on the concept of wrongs. In 3.2 I focus on the concepts of capacities and knowers. In 3.3 I focus on the concepts of distinctiveness and discrimination. In 3.4 I focus on the concept of something being incidentally epistemic. In 3.5 I focus on the concepts of intentions and experiences. In 3.6 I focus on the concept of epistemic purity. In 3.7 I focus on the concepts of epistemic context and harm. Finally, in 3.8, I present my new account of epistemic injustice, and compare it to the Frickerian account and the enumerative and pluralist methods. 


\section{Chapter One: What is Epistemic Injustice?}

\section{0: Motivations}

"Epistemic injustice" is a term that was coined by Miranda Fricker in 1998, used to describe the phenomenon of perceived credibility tracking social power, with people with more social power being assigned a greater degree of credibility, and people with less social power being assigned a lesser degree of credibility. Over the years, the concept of epistemic injustice has expanded to contain a greater number of more specific phenomena, with by far the most influential change to the concept of epistemic injustice coming from Fricker herself with the publication of Epistemic Injustice in $2007 \cdot \cdot^{4}$

Epistemic injustice is an important concept which brings to light certain injustices which had previously gone widely unrecognized, ${ }^{5}$ such as, for example, people being less likely to be believed when giving testimony owing to factors that ought to be irrelevant, such as sex or ethnicity, or people being unable to understand important aspects of their own experience, or make themselves understood to others, owing to certain kinds of people being systematically prevented from having a voice in the generation of concepts that accurately reflect or describe their experiences, such as medical and legal concepts. When it comes to understanding the concept of epistemic injustice, Epistemic Injustice is a very important book. It has received significant uptake, so far being cited over 2600 times, ${ }^{6}$ and it brings the idea of epistemic injustice into mainstream philosophical discussion. As epistemic injustice is a fairly young area of philosophy, the information in Epistemic Injustice plays a central role: Fricker's book provides what is essentially the only account of epistemic injustice-while various authors have argued for localized changes to the Frickerian account, there is no actual alternative account-and it is what a vast majority, if not all, of the authors who have

\footnotetext{
${ }^{4}$ Fricker's papers on epistemic injustice prior to Epistemic Injustice have been cited considerably fewer times than the book, and, relating to this, the general understanding of epistemic injustice that can be taken from the book is utilized considerably more than the ones in Fricker's earlier papers.

5 There is some controversy surrounding the actual origins of the concept of epistemic injustice. It has been argued that the idea of epistemic injustice, though not named as such, exists in black feminist literature that predates Fricker's work; see McKinnon, 2016, p.439.

${ }^{6}$ As of August 2019, according to Google Scholar.
} 
written on epistemic injustice since its publication base their understanding of epistemic injustice on.

It is therefore both unfortunate, and important, that the Frickerian account is ambiguous and incomplete. Epistemic Injustice hints at necessary and sufficient conditions for something to qualify as an epistemic injustice, but does so far from explicitly, and fails to clearly define what appear to be key terms. This is not to say that Fricker herself is particularly blameworthy for this, or that Epistemic Injustice is overall an ambiguous or incomplete work, or even that we should conclude that there is nothing useful to be taken from the account that it develops. What it does mean, however, is that we are left unclear of what epistemic injustice actually is.

This is both philosophically and practically problematic. Philosophically speaking, we should care about having concepts that are clearly defined, with the necessary and sufficient conditions of something being an epistemic injustice clearly identified. As it is, our understanding of the concept of epistemic injustice is, for want of a better way of putting it, "messy" and philosophically unsatisfying. Practically speaking, "epistemic injustice" is essentially a diagnosis that is given to a real-world problem, but in order to be able to use it as such, we need to know what the necessary and sufficient conditions of something being an epistemic injustice are. Being able to accurately identify and label things as epistemic injustices would allow us to both recognize previously underrecognized (or entirely unrecognized) injustices, and, understanding their true nature, have a better chance of overcoming them. As political and social issues increasingly lean towards questions of identity, experience, truth, and power, the concept of epistemic injustice is relevant not just to academic discussion or fringe cases, but it also holds a wide-ranging practical importance. Having a clear understanding of it, then, is something that we have reason to have an interest in.

Although the Frickerian account of epistemic injustice is ultimately unsatisfactory, there are reasons to try to understand it. In particular, Fricker's work is central to the topic of epistemic injustice and has had a lot of influence, so in order to understand any of the literature on epistemic injustice, one has to have some understanding of the Frickerian account; also, the Frickerian account does provide us with some workable 
material, and something of an understanding of the concept of epistemic injustice: it just isn't workable as an account of epistemic injustice as is.

In this thesis, I aim to do three things. Firstly, in Chapter One, I give an overview of the Frickerian account of epistemic injustice, and show that it is ambiguous and incomplete. Secondly, in Chapter Two, I show the ways in which the wider literature on epistemic injustice has attempted to deal with the ambiguity and incompleteness of the Frickerian account. I argue that we can see in the literature two main approaches to addressing this ambiguity and incompleteness. Neither, however, succeeds in solving the problem of clarifying what epistemic injustice is, and both introduce new problems of their own. Finally, in Chapter Three, working from the key concepts of the Frickerian account, I construct an alternative account of epistemic injustice that, unlike the Frickerian account itself, is both philosophically satisfying and practically useful, while respecting the general spirit of the Frickerian account and other authors' contributions.

\section{1: Origins}

Fricker first introduced the concept of epistemic injustice in her 1998 paper Rational Authority and Social Power: Towards a Truly Social Epistemology. In this paper, "epistemic injustice" refers to a mismatch between a person's actual credibility, and the credibility that they are perceived to have by others, owing to "some social pressure on the norm of credibility to imitate the structures of social power" (Fricker, 1998, 170). In other words, epistemic injustice occurs when we assign less credibility to a person who has little social power qua person who has little social power, and more credibility to a person who has greater social power qua person who has greater social power. To this, Fricker adds,

...when people are unjustly denied credibility, they are thereby unjustly denied the opportunity to participate in the spread of knowledge - the 'original' practice from which the concept of knowledge arises. This means that the epistemic injustice to which they are subjected is not only a matter of their credibility being undermined, but also their status as knowers. (Fricker, 1998, 176) 
In other words, if a person is not taken as credible, they are not able to participate in the spread of knowledge, as their testimony will not receive uptake. Epistemic injustice therefore consists of two wrongs: the wrongful undermining of a person's credibility, and the wrongful undermining of their ability to spread knowledge.

This account of epistemic injustice is not the final form that Fricker's account of epistemic injustice takes. In 1999, Fricker published the paper Epistemic Oppression and Epistemic Privilege. In this paper, Fricker introduces a new form of epistemic injustice, which she calls "hermeneutical injustice". To understand the concept of hermeneutical injustice, we must place it in the context of shared social understandings. One's identity and social experiences, Fricker points out, affect one's "interpretive habits"; that is, who a person is influences what elements of a situation they take to be relevant to interpreting that situation. People with different identities and social experiences will therefore be likely to pick out different elements of the same situation as relevant, and thus interpret the situation differently. This difference in interpretive habits can lead to a failure of proper understanding on the part of those who, owing to their identity and social experiences, fail to pick out certain vital elements of a situation as important. Fricker elaborates:

If, for example, someone fails to pick up on the significance for a given interaction the fact that only one of the two participants has the power to fire the other, or to fail the other in exams, or to prevail in a physical fight, then she may misunderstand the nature of the interaction altogether. (Fricker, 1999, 207)

Fricker argues that this personal-level failure to accurately interpret a situation can happen on a larger scale, where there is a collective failure to pick out significant factors of a situation as important. And, while this in theory could happen to anyone, she emphasises that the social experiences of those who lack social power are more likely to be excluded from our understandings, which results in their social experiences being "obscure and confusing, even for them, in a way which limits or distorts collective social understanding more generally" (Fricker, 1999, 208). Fricker calls these collective failings "hermeneutical injustices", which, she says, are a kind of epistemic injustice "so long as the hermeneutical practice in question is one through which we gain knowledge." (Fricker, 1999, 208). 
At this stage, Fricker's account allows for epistemic injustice to take two forms. The first occurs when someone is denied credibility owing to their lack of social power, and the second-"hermeneutical injustice"-occurs when someone's experiences are left obscure and confusing, even to the person going through that experience, owing to there being a collective failure to recognize important aspects of that experience as being important.

However, this account of epistemic injustice is still not the final form that Fricker's account of epistemic injustice takes. Rather, this account was developed in Fricker's next publication on the topic: Epistemic Injustice.

\section{2: Epistemic Injustice}

Fricker's next publication on epistemic injustice was her 2007 book Epistemic Injustice. This book builds on Fricker's previous two papers on the topic of epistemic injustice. The kind of injustice that was described simply as "epistemic injustice" in Rational Authority and Social Power provides the building blocks for one of two kinds of epistemic injustice that Epistemic Injustice describes: "testimonial injustice". The concept of "hermeneutical injustice" from Epistemic Oppression and Epistemic Privilege provides the building blocks for the other, which in Epistemic Injustice is still referred to as "hermeneutical injustice".

Epistemic Injustice is mostly dedicated to describing and discussing testimonial injustice, which Fricker describes as the result of "identity-prejudicial credibility deficit(s)" (Fricker, 2007, 28). This stands in contrast to testimonial injustices (which in Rational Authority and Social Power were referred to merely as "epistemic injustice") being explained purely in terms of power relations in Rational Authority and Social Power. An "identity-prejudicial credibility deficit" occurs when a prejudice that a hearer in a testimonial exchange holds causes the hearer to diminish how credible she takes the speaker to be. For example, the hearer may hold a prejudice against women, incorrectly thinking them to be emotional rather than rational, and hence attributes less credibility to them as a result; or a hearer may hold a prejudice against people of colour, mistakenly thinking them to be uneducated, and therefore attribute less credibility to them as speakers than they deserve; or a hearer may hold a prejudice 
against the elderly, falsely thinking them to be out of touch, and therefore attribute less credibility to the word of an elder than they would a younger person; etc. In all of these kinds of cases, the hearer takes the speaker's testimony to be less credible than they otherwise would have, in virtue of an identity-prejudicial credibility deficit.

Prejudices, Fricker notes, particularly those which contain stereotypes about people of a given identity not being reliable sources of information, historically tend to be held against those who lack social power. Fricker gives the examples of women, black people, and the working class (Fricker, 2007, 32). This way of understanding testimonial injustice is therefore not radically different from the power-relational understanding presented in Rational Authority and Social Power. However, it is more nuanced: according to the identity-prejudicial understanding, anyone, regardless of how powerful or powerless, can in theory suffer from a testimonial injustice, so long as the hearer is prejudiced against the speaker's identity in a way that causes the hearer to diminish the speaker's credibility.

This nuance is played out in Epistemic Injustice's identifying of two kinds of testimonial injustice: "incidental" testimonial injustice, and "systematic" testimonial injustice. Incidental testimonial injustice occurs when an agent is subject to a testimonial injustice owing to the hearer holding a prejudice against an aspect of the agent's identity which only holds social significance in specific, limited contexts. Fricker gives the example of a conference attended primarily by research scientists and historians of science, with a small number of philosophers of science also in attendance. Over the course of the conference it becomes evident that the research scientists and the historians of science regard the philosophers as being

out of touch with the realities of scientific practice, so much so that they are, frankly, held in some intellectual distain. In this context, it would seem, simply falling into the identity category "philosopher of science" renders one's word likely to be dismissed as the vain speculations of an out-of-touch academic. (Fricker, 2007, 28)

The kind of testimonial injustice experienced by the philosophers of science at this conference is incidental, rather than systematic, as the identity prejudice that the 
scientists and historians hold against the philosophers does not track across other areas of the philosophers' lives: outside of this one conference, the individuals in question are generally taken to be credible.

In contrast to incidental testimonial injustice, there is systematic testimonial injustice, where the aspect of the speaker's identity which is causing them to experience a testimonial injustice also tracks into other areas of their life. For example, let us imagine that one of those philosophers in the previous example is a woman of colour, who, owing to widely held sexist and racist prejudices in her society, which stereotypes women of colour as being uneducated and irrational, is treated as lacking credibility not just at one specific conference, but in many aspects of her life. The testimonial injustice she experiences qua woman of colour is, therefore, not incidental, but systematic.

While a majority of the book is dedicated to discussing testimonial injustice, Fricker devotes the final chapter of Epistemic Injustice to hermeneutical injustice, which is explained in a similar way to how it was in Epistemic Oppression and Epistemic Privilege. Fricker defines hermeneutical injustice as "the injustice of having some significant area of one's social experience obscured from collective understanding owing to hermeneutical marginalization" (Fricker, 2007, 158), where "hermeneutical marginalization" refers to certain kinds of people being prevented from participating in practices which generate collective social meanings, and as such have the true nature of their experiences kept in the dark, both to themselves and to others.

As with testimonial injustice, Fricker identifies an incidental and a systematic form of hermeneutical injustice. In incidental cases, the hermeneutical marginalization is "localized and one-off" (Fricker, 2007, 158); for this, Fricker gives an example from the Ian McEwan novel Enduring Love, in which the protagonist Joe is being persistently followed, phone-called, and generally not let alone by a man called Jed, who is utterly obsessed with him. When Joe attempts to communicate his experience of being stalked by Jed to his (Joe's) partner, she thinks the situation of Jed being so enamoured with Joe is funny, and thinks that Joe is taking the situation overly seriously. When Joe contacts the police to report Jed's behaviour in the hope of putting a stop to it, he is dismissed by the officer when, after being questioned, Joe confirms that Jed is neither harming nor threatening to harm Joe, Joe's property, or any third parties or their property, and that 
Jed is not behaving in a manner that could be classed as obscene. There are, in other words, no legal concepts for the officer to tack Jed's behaviour onto, and thus the officer is unable to interpret the situation as anything but trivial, and thinks that Joe is wasting police time. While Joe is in this case unable to make himself understood-both his partner and the police are unable to interpret Jed's behaviour correctly as unsettling, and disruptive to Joe's daily life, owing to its lack of obvious threatening or illegal qualities-it is a localized case of Joe being unable to make himself understood, which does not track into other areas of his social experience. In Fricker's words,

The injustice does not stem from any structural identity prejudice-on the contrary, he suffers the injustice not because of, but rather in spite of, the social type he is. Clearly Joe's hermeneutical injustice is not a systematic case; it is incidental. (Fricker, 2007, 158)

Let's take a moment to consider what Fricker means here by "the social type (Joe) is". Joe is an educated, white, heterosexual male: part of a group which has not historically been prevented from creating concepts through which to describe and have their experiences understood. While it is harmful to Joe that he is not able to communicate, and have others understand, his experience of Jed's behaviour, this isn't happening owing to a social structure that causes hermeneutical injustices to befall people like Joe in many areas of life.

Before moving on, I will note that one may be inclined to disagree with Fricker's assessment that Joe is suffering this hermeneutical injustice in spite of, not because of, his social type. One could interpret Joe's trouble making himself understood to be owing to his social type: we might assume that he can't get people to understand that Jed following him around is genuinely distressing because he (Joe) is a man. It might seem that, were Joe a woman, both Joe's partner and the officer would have had an easier time understanding why having a strange man following him around would be something that it would be reasonable for Joe to find distressing. I therefore think that it is important that, in order to understand incidental hermeneutical injustice, we interpret both the example, and Fricker's statement that the hermeneutical injustice that occurs is happening in spite of, not because of Joe's social type, in the following way. 
Joe is of a privileged social type: he is a white, educated, heterosexual male. When Joe's experiences fall in line with those experiences that are common to those of his social type, he both understands those experiences himself, and is able to be understood by others when he articulates those experiences. This stands in contrast to people who are of an underprivileged social type, who, when their experiences fall in line with those experiences that are common to those of that underprivileged social type, may be unable to understand those experiences themselves, and be unable to make themselves understood by others when they attempt to articulate them, because of hermeneutical marginalization. In this particular instance, Joe has the misfortune of having an experience that is atypical to his social type, and therefore comes to suffer an incidental hermeneutical injustice. We should interpret Fricker saying that it is in spite of, not because of, his social type that Joe suffers this injustice to mean that it is in spite of his social type that Joe comes to experience a hermeneutical injustice at all given his general hermeneutical privilege, rather than interpret her to be saying that it is in spite of, not because of, his social type that Joe can't get his partner or the police to understand that being stalked by Jed is a genuine and distressing problem.

Systematic hermeneutical injustice, on the other hand, is caused by a "wide-ranging and persistent hermeneutical marginalization" (Fricker, 2007, 159). To illustrate this, Fricker gives two examples from Susan Brownmiller's memoir about the women's liberation movement. The first example is of a woman who was suffering from undiagnosed postpartum depression. Because she and those around her had no concept of postpartum depression, the woman both blamed herself and was blamed by her husband for what we may assume looked like a lack of love for her child, or an unwillingness to parent. The second example is of another woman who-before there was a legal or social concept of sexual harassment-resigned from her job after persistent sexual harassment from her boss, and, owing to that lack of the concept of sexual harassment, was unable to describe, when applying for an unemployment benefit, why she had left her job, beyond that the reason was "personal". Subsequently, she was denied the unemployment benefit. In these cases, each individual woman's experience was the result of women's collective voices being kept out of spaces where legal and medical concepts are constructed, and relatedly, women being isolated from 
others with similar experiences: a wide-ranging and persistent hermeneutical marginalization.

Alongside these accounts of testimonial and hermeneutical injustice, where a hearer comes to deflate the credibility they assign to a speaker, or where a person finds themselves unable to understand or communicate their experience to others, owing, in both instances, to something ethically problematic-prejudice; hermeneutical marginalization-Fricker also provides an explanation of what is occurring in cases where a hearer comes to deflate the credibility they assign to a speaker, or where a person finds themselves unable to understand or communicate their experience to others, when there is nothing ethically problematic at play. Fricker gives the examples of a shy person whose shifty manner gives the impression of insincerity (Fricker, 2007, 41), and a person who suffers from a medical condition that causes unusual social behaviour at a time in history when that condition is not yet understood (Fricker, 2007, 152). ${ }^{7}$ These cases, according to Fricker, are examples of "epistemic bad luck" rather than examples of epistemic injustice, as no one is wronged, though they may be harmed: these are "cases of innocent error... (there is) no epistemic culpability, and no ethical culpability" (Fricker, 2007, 42-43).

Fricker also explains what to make of cases where a hearer deflates the credibility they assign a speaker owing not to something ethically problematic, but rather, owing to something epistemically problematic. Fricker gives the example of a philosopher, before meeting another philosophy professor from a different institution, doing an extremely careless web search of his name and, owing to her poor research, coming to believe that this other professor is a medic, rather than the fellow philosophy professor that he actually is. Resultingly, when talking to him about philosophical matters, she does not take him to be credible (Fricker, 2007, 22). In such instances, like with epistemic bad luck, Fricker argues that an epistemic injustice has not occurred, as "an ethically nonculpable mistake cannot undermine or otherwise wrong a speaker" (Fricker, 2007, 22).

\footnotetext{
7 This example may seem to contradict with Fricker's previous example of a woman suffering a hermeneutical injustice relating to her post-partum depression. In the interests of being charitable, we should interpret the example of epistemic bad luck as referring to a very rare and complicated medical condition that has not yet been discovered, owing not to any prejudice or inequality, but to a lack of adequate technological advancement to detect it.
} 
In summary, at this stage, the Frickerian account of epistemic injustice looks like it consists of two types of injustice, each of which can take two forms. The first, "testimonial injustice", occurs when someone's word is taken by a hearer to be lacking in credibility, owing to the hearer holding an identity prejudice against the speaker. This can take an incidental form, where the identity prejudice is one that is only held against the speaker in localized situations, and a systematic form, where the identity prejudice is one that is persistent and wide-ranging. The second, "hermeneutical injustice", occurs when someone is unable to understand or communicate their experience owing to there being a collective hermeneutical lacuna, which comes about because of the exclusion of certain kinds of people from the generation of collective meanings. This too can take an incidental form, where someone suffers a hermeneutical injustice in spite of, not because of, their identity, and a systematic form, where someone suffers a hermeneutical injustice because of their identity. This is what I will call the "basic interpretation" of the Frickerian account, owing to it being the most simple way of interpreting how Fricker conceptualizes epistemic injustice.

However, as we already noted, Epistemic Injustice contains a passage in the introduction which indicates that the concept of epistemic injustice goes beyond what we get from the basic interpretation. This is where problems start to arise.

\section{3: Ambiguity and Incompleteness}

In the introduction of Epistemic Injustice, Fricker states:

"This book explores the idea that there is a distinctively epistemic kind of injustice. There are a number of phenomena that might be brought under the general head of epistemic injustice. Given how we normally think about justice in philosophy, the idea of epistemic injustice might first and foremost prompt thoughts about distributive unfairness in respect of epistemic goods such as information and education. In such cases we picture social agents who have an interest in various goods, some of them epistemic, and question whether everyone is getting their fair share. When epistemic injustice takes this form, there is nothing very distinctively epistemic about it, for it seems largely incidental that the good in question can be characterized as an epistemic good. 
By contrast, the project of this book is to home in on two forms of epistemic injustice that are distinctively epistemic in kind, theorizing them as consisting, most fundamentally, in a wrong done to someone specifically in their capacity as a knower. I call them testimonial injustice and hermeneutical injustice." (Fricker, 2007, 1)

In this passage, Fricker is thinking of epistemic injustice as consisting (actually or potentially) of more than just testimonial and hermeneutical injustice. Her talk of "a number of phenomena that might be brought under the general head of epistemic injustice" and "forms" of epistemic injustice imply that we could reasonably conceive of epistemic injustice as something that consists of more than just testimonial and hermeneutical injustice. However, Fricker's intended scope of epistemic injustice, and the necessary and sufficient conditions for something being an epistemic injustice, are unclear, for reasons I will outline below.

Firstly, consider Fricker's talk of "how we normally think about justice in philosophy" (Fricker, 2007, 1). On the one hand, she could be making a criticism of how justice is normally thought about in philosophy, and by extension objecting to what, thinking of justice in this way, we might take epistemic injustice to be, e.g. unfairly distributing education and information. On the other hand, she might be saying that, owing to there being an existing way that justice is normally thought about in philosophy, we already have one way that we might understand epistemic injustice-thinking of it as consisting of issues such as the unfair distribution of education and information-and be using this book to present some more kinds of epistemic injustice alongside those more immediately obvious ones. The intended scope of epistemic injustice is therefore unclear from the start.

Secondly, it is not clear what Fricker means by "distinctively epistemic": she never defines the term. However, the idea of something being distinctively epistemic is evidently important given the number of times it is mentioned. Instead of a positive definition of the term, Fricker offers an example of something which is not a distinctively epistemic kind of injustice, viz. the unfair distribution of epistemic goods (such as education and information). On her view, this does not qualify as distinctively 
epistemic injustice, because "it seems largely incidental that the good in question can be characterized as an epistemic good".

How this should be interpreted depends on what Fricker means by "incidental". Given common usage of the word, she could be using it to mean something like "unimportant", or she could be using it to mean something like "by chance". For the sake of clarity and conciseness, I will, from here on in, treat cases where "it seems largely incidental that the good in question can be characterized as an epistemic good" as "incidentally epistemic". Returning to the case of depriving someone of an education as an incidentally epistemic injustice, we could take Fricker to mean something like this: the fact that it is something epistemic that the victim is being deprived of is not important; rather what's important is, perhaps, just that they are being deprived of something, where the deprivation itself is important and what precisely they are being deprived of is not. Alternatively, when Fricker says that the injustice of depriving someone of an education is "incidentally epistemic", she could be saying that the fact that they are being deprived of something epistemic is by chance: such an instance could come about if the victim was being deprived of an education just because they are being deprived of things generally and an education just happened to be one of those things, for example, as opposed to them being deprived of an education because the person who is depriving them specifically does not want them to be educated. If we take Fricker to require that an injustice be non-incidentally epistemic as a condition of it being an epistemic injustice, then this difference, while subtle, is important in how we analyse an injustice to decide whether or not it is an epistemic injustice. I will return to this point in greater detail in Chapter Three.

Fricker's negative example of distinctively epistemic injustice leaves us uncertain of what it means for something to be distinctively epistemic. A positive example would perhaps be more useful, however, any obvious such example is lacking. The closest that we get to a positive example could possibly be taken from where Fricker says:

By contrast, the project of this book is to home in on two forms of epistemic injustice that are distinctively epistemic in kind, theorizing them as consisting, most fundamentally, in a wrong done to someone specifically in their capacity as a knower. (Fricker, 2007, 1) 
It could be that here she is saying that for an injustice to be distinctively epistemic, it must consist, most fundamentally, in a wrong done to someone in their capacity as a knower. However, this is not something that we can claim with certainty, as it could be the case that Fricker is saying that the two forms of epistemic injustice that she will be focusing on happen to consist in a wrong done to someone specifically in their capacity as a knower, rather than that all forms of distinctively epistemic injustice must consist in a wrong done to someone specifically in their capacity as a knower. Further, even if Fricker is suggesting that all forms of distinctively epistemic injustice consist in a wrong done to someone specifically in their capacity as a knower, it illuminates little, because what it means for a wrong to be done to someone specifically in their capacity as a knower is, at this stage, left open, other than that testimonial and hermeneutical injustice fundamentally consist of it.

In order to learn what is meant by "a wrong done to someone specifically in their capacity as a knower", we need to move away from the introductory passage and further into the book. In Chapter Two of Epistemic Injustice, Fricker gives what could be taken as an explanation as to what it means to wrong someone in their capacity as a knower: "undermine, insult, or otherwise withhold a proper respect for the speaker qua subject of knowledge" (Fricker, 2007, 20).

Here, Fricker is not talking about epistemic injustice generally, but is talking about why a particular case does not qualify as a testimonial injustice (because it does not undermine, insult, or otherwise withhold a proper respect for the speaker qua subject of knowledge). It therefore is something that we should not necessarily think applies to epistemic injustice as a whole. On the other hand, cases that "undermine, insult, or otherwise withhold a proper respect for the speaker qua subject of knowledge" do intuitively sound like cases of "a wrong done to someone specifically in their capacity as a knower".

However, assuming that wronging someone in their capacity as a knower minimally includes undermining, insulting, or withholding a proper respect for them, I'm not sure that we are able to understand, as we were hoping to, "distinctively epistemic" as "a wrong done to someone specifically in their capacity as a knower". Here's why: withholding education or information from a person also seems to involve 
undermining, insulting or otherwise withholding a proper respect for that person as a "subject of knowledge". Barring someone from receiving an education seems like it does undermine that person-it would, for example, significantly limit their future opportunities. Likewise, withholding information from a person could certainly be insulting, if that information was being withheld owing to the potential receiver of that information unfairly being perceived or treated as though they were, for example, too unintelligent, immature, or untrustworthy to be given that information. Perhaps, then, it is more plausible to think of the concepts of "distinctively epistemic" and "a wrong done to someone specifically in their capacity as a knower" as separate concepts, which leaves us once again in the dark as to what "distinctively epistemic" means.

Setting aside the confusion around the notion of epistemic distinctiveness for the moment, let's turn our focus to what might be meant by "capacity as a knower". To begin with, what is meant by "knower"? This is not something that Fricker explains at this point in the book, though an answer can be found near the end of Epistemic Injustice, where Fricker states, "essentially what it is to be a knower is to participate in the sharing of information" (Fricker, 2007, 145). This seems to fall in line with Rational Authority and Social Power: Towards a Truly Social Epistemology, where Fricker talks about how being taken as being non-credible leads to the victim's status as a knower being undermined, as the victim is unjustly denied the opportunity to participate in the spread of knowledge. While credibility only really applies to testimonial injustice, being prevented from participating in the spread of knowledge or sharing of information could apply to hermeneutical injustice too: after all, if one does not have the concepts to make oneself understood, then one cannot spread knowledge about their experience. Perhaps, then, we could jointly define "knower" and one's "capacity" as one as "to, or to be able to, participate in the spread of knowledge/the sharing of information". On the other hand, this might not be right: after all, wrongly withholding education or information from someone does seem like something that would prevent someone from participating in the spread of information, as, prima facie, if someone withholds education or information from someone about a particular topic, then the person who the education or information was withheld from cannot participate in the spread of that information. It therefore seems that, while Fricker likely intends to define "knower" and 
one's "capacity" as one as "to, or to be able to, participate in the spread of knowledge/the sharing of information", this definition is tangled up in the confusion about whether or not the unfair distribution of epistemic goods such as education and information is an epistemic injustice or not, which is tangled up in the confusion about what it means for something to be distinctively epistemic.

We therefore have a problem. We know that the Frickerian concept of epistemic injustice likely goes beyond just testimonial and hermeneutical injustice. However, owing to Fricker failing to provide definitions for key terms and concepts, or to provide the necessary and sufficient conditions of something being an epistemic injustice, we don't know, beyond testimonial and hermeneutical injustice, what epistemic injustice actually is. And we have reason to want to know this: without knowing what makes something an epistemic injustice, we are unable to reliably identify new kinds of epistemic injustice.

At this point, we are left with one big question: what makes something an epistemic injustice? Clearly, we are not going to find the answer to this question just by looking at Epistemic Injustice. In the next section, I will turn to the clarifications and changes that have been made to the Frickerian account by Fricker herself in papers published after Epistemic Injustice, and discuss whether they help us to answer this question.

\section{4: Developments to the Frickerian Account}

In the previous section, we discussed what Fricker's overarching account of epistemic injustice appears to be, and concluded that, from the information we are given in Epistemic Injustice, we are unable to say what epistemic injustice is, beyond that it contains the concepts of testimonial injustice and hermeneutical injustice. In this section, I consider whether Fricker's recent work since the publication of Epistemic Injustice helps to clarify her account.

In Epistemic Injustice, how Fricker was defining "epistemic injustice" was not clear. In Replies to Alcoff, Goldberg and Hookway on Epistemic Injustice, Fricker says that she defines epistemic injustice as "a species of injustice in which someone is insulted or undermined specifically in their capacity as a knower" (Fricker, 2010, 175). 
Previously, I highlighted that it was uncertain whether someone being insulted or undermined in their capacity as a knower was something that was a condition of something being an epistemic injustice, or an incidental feature of testimonial and hermeneutical injustice specifically. The above quote implies that the insulting or undermining of someone in their capacity as a knower is a definitive feature of any kind of epistemic injustice.

A central question now concerns how to make sense of her earlier idea of epistemic injustices being distinctively epistemic, in light of Fricker's current focus on someone being "insulted or undermined specifically in their capacity as a knower". In Epistemic Injustice, emphasis appeared to be put on the importance of an injustice being distinctively epistemic, but here, that emphasis seems to have switched to "insulted or undermined specifically in their capacity as a knower".

Something in the way of an explanation could be found in Fricker's apparent desire to eliminate the distinction between distinctive and distributive injustices that was set up in Epistemic Injustice. In the book, she spent some time distinguishing between injustices involving the unfair distribution of epistemic goods, and injustices which were "distinctively epistemic in kind". While it was not entirely clear, it seemed possible that injustices being distinctively epistemic was a condition of them being epistemic injustices. The change in emphasis from "distinctively epistemic" to "insulted or undermined specifically in their capacity as a knower" could be a result of Fricker wanting to move away from this distinction between distinctively epistemic and distributive injustices.

In Replies to Alcoff, Goldberg and Hookway on Epistemic Injustice, Fricker states

[The concept of epistemic injustice] should be thought of as including distributive forms of epistemic injustice, such as unequal access to epistemic goods like information, or education. In this I agree with David Coady... who rightly affirms that distributive forms of epistemic injustice are, contrary to what I seem to say at the start of the book, distinctively epistemic injustices. It would have been better if I had placed the emphasis on my aim of unveiling forms of discrimination—epistemic discrimination... (Fricker, 2010, 175) 
Fricker reiterates and expands on this sentiment in Epistemic Justice as a Condition of Political Freedom, stating

I shall first briefly revisit the broad idea of 'epistemic injustice', explaining how it can take either distributive or discriminatory form... (Fricker, 2013, 1317)

And

...in previous work... the focus was exclusively on what I would now prefer to specify as discriminatory epistemic injustice. This contrasts with distributive epistemic injustice - the unfair distribution of epistemic goods such as education or information-which is an important kind of social injustice in its own right, and may often be closely entwined with the discriminatory kind. (Fricker, 2013, 1318)

There are two ways which we could interpret this. The first is to suggest that, actually, it does not matter whether or not an injustice is distinctively epistemic when it comes to identifying epistemic injustices. The second is to suggest that the injustice being distinctively epistemic is still important when identifying epistemic injustices, but that Fricker was either mistaken to think or to imply that distributive injustices are not distinctively epistemic.

Either way, we now have a new concept to deal with: "discriminatory epistemic injustice”, which describes injustices that don't involve distribution. Though it may be a matter of poor wording, the concept of "discriminatory epistemic injustice" is confusing: it is not clear that testimonial and hermeneutical injustices are any more meaningfully discriminatory than injustice involving the unfair distribution of epistemic goods such as education or information. Consider, for example, countries in which girls have limited access to schooling compared to boys owing to sexist attitudes in that country: while this is an injustice that involves the unfair distribution of epistemic goods, those goods are obviously being distributed in a discriminatory way. The lines between distributive and discriminatory epistemic injustice therefore seem blurred. While Fricker does allow that distributive epistemic injustice "may often be closely entwined with the discriminatory kind", this seems like less of an entwining and more of a lack of a meaningful distinction. 
Fricker does, however, give us some information about an important feature of discriminatory epistemic injustices: they must be unintentional.

Essentially I have in mind the question of intention, or rather its absence. In testimonial injustice the absence of deliberate, conscious manipulation is definitive, at least in my conception. I was trying to bring out a phenomenon that is easy to miss, and in need of a name. In this kind of epistemic injustice, the hearer makes a special kind of misjudgement of the speaker's credibility-one actually clouded by prejudice. And this is importantly different from any deliberate misrepresentation of someone's true or reasonable beliefs as false or rationally unfounded, for when that happens the perpetrator herself need not misjudge the other's epistemic status at all... in the case of hermeneutical injustice now, the hearer who cannot understand because she lacks sufficiently shared concepts with the speaker might be trying in earnest to understand, but is unable because of an objective difficulty. She is not deliberately manipulating, concealing, or blanking anything. (Fricker, 2017, 54)

We therefore also need to consider that forms of discriminatory epistemic injustice must not be intentional: it must be the case that the perpetrator of the injustice genuinely believes the speaker to be lacking in credibility, or genuinely cannot understand them; and it cannot be the case that they actually take the victim to be credible, or can actually understand them, but are choosing to behave as though they do not for their own purposes. In Epistemic Injustice Fricker discusses cases where epistemic harm is caused, but the perpetrator is neither ethically nor epistemically culpable (such a case is a matter of bad luck, or innocent error, where it is not an epistemic injustice) and cases where epistemic harm is caused, but the perpetrator is epistemically, but not ethically culpable (also not epistemic injustice); this addition tells us what to make of cases where epistemic harm is caused for which the perpetrator is ethically culpable which doesn't involve the perpetrator making an epistemic error, at least in cases of discriminatory epistemic injustice. Whether or not this stands with distributive epistemic injustice remains unclear. It could be that in order for something to be an epistemic injustice, it must be unintentional, and unintentionality is therefore a necessary condition of epistemic injustice; alternatively, it could be that only 
discriminatory epistemic injustice must be unintentional, while distributive epistemic injustices can be intentional.

\section{5: Summary}

As it stands, the Frickerian account of epistemic injustice is neither robust nor clear, nor can we use it to identify epistemic injustices beyond testimonial and hermeneutical injustices, except knowing that it can, according to Fricker's more recent work, include the unfair distribution of epistemic goods. While Fricker's work hints at concepts that may make up the necessary and sufficient conditions of something being an epistemic injustice, those concepts are not defined clearly, and their relation to one another and how this works to form an account of epistemic injustice is very ambiguous.

On the Frickerian account, it seems like there should be more to epistemic injustice than just testimonial injustice and hermeneutical injustice. However, we are not given any real indication of what these are, beyond that distributive injustices are also included.

This leaves two general gaps in the Frickerian account. Firstly, and most importantly, we're missing a clearly identified set of necessary and sufficient conditions for something being an epistemic injustice. Secondly, we don't know what kinds of epistemic injustice there are beyond testimonial and hermeneutical injustice, and some distributive injustices. In order to fill the second gap, we need to fill in the first, as we cannot say what other kinds of epistemic injustices there are without knowing what makes something an epistemic injustice. However, as I will illustrate in Chapter Two, the literature on epistemic injustice outside of Fricker's work tends to focus on filling the second gap without satisfactorily addressing the first. 


\section{Chapter Two: Moving Past the Frickerian Account}

\section{2.o Beyond Fricker}

Fricker's work on epistemic injustice, particularly Epistemic Injustice, has received a great deal of uptake, and sparked a lot of literature utilizing the concept of epistemic injustice. In this chapter, I focus how others have extended the concept of epistemic injustice beyond the basic interpretation of the Frickerian account.

Within this literature, there are two main methods approaches to this extension. Firstly, there is what I will call "the enumerative method". The enumerative method involves taking something like the basic interpretation-"epistemic injustice consists of testimonial injustice and hermeneutical injustice"-and adding new kinds of epistemic injustice to that list, using the Frickerian account as the one and only account of epistemic injustice, and adding to it. Secondly, there is what I will call "the pluralist method". The pluralist method involves taking the Frickerian account as an account of epistemic injustice (one of many possible accounts), rather than the account of epistemic injustice (the one and only account), and arguing that there can be multiple different accounts of epistemic injustice that are all equally valid. Note that the enumerative method is something that has come about organically in the literature, while the pluralist method has been explicitly argued for by two authors.

In this chapter, I argue that neither the enumerative method nor the pluralist method helps us to better understand epistemic injustice, as neither fills the first gap (viz. that we don't have a clearly defined set of necessary and sufficient requirements for something being an epistemic injustice), and both add further problems of their own.

\section{1: Enumeration and Pluralism}

As mentioned, the enumerative method involves taking something like the basic interpretation of the Frickerian account, and adding new kinds of epistemic injustice to that list of injustices (a list that currently consists only of testimonial injustice and hermeneutical injustice). Doing so addresses the second gap in the Frickerian account, i.e. that there is probably more to epistemic injustice than just testimonial injustice and 
hermeneutical injustice, but we don't know what. The result of the enumerative approach is an account of epistemic injustice that primarily takes the form of a list of kinds of epistemic injustices. Let's consider what has been included in this list. ${ }^{8}$

First, there is argumentative injustice. In his 2010 paper Argumentative Injustice, Bondy introduced the idea of argumentative injustice, which he presents as analogous but different to testimonial injustice. Argumentative injustice occurs when an arguer is judged to have either an excess or a deficit of credibility as an arguer, owing to an identity prejudice in the mind of a hearer. This can be in the form of the hearer attaching too much or too little credibility to the premises of the argument, or to the degree to which the premises support the conclusion. Bondy notes that as the subject of argumentative injustice, you are harmed as an arguer, not a knower, but argues that "much of what we know comes to us through arguments, so our capacity as arguers often has a bearing on our capacity as knowers" (Bondy, 2010, 266).

Second, there is the idea of epistemic injustice involving procedural knowledge alongside propositional knowledge. In her 2011 paper Knowing How and Epistemic Injustice, Katherine Hawley argues that epistemic injustice can cover both "knowingthat" and "knowing-how" judgements on part of the hearer. Fricker addressed judgements of knowing-that (propositional knowledge) with testimonial injustice: unfair judgements that a person does not know that something. Hawley introduces epistemic injustice relating to knowledge-how (procedural knowledge): unfair judgements that a person does not know how to do something. She gives two real-world examples: one where American orchestras who utilized anonymous auditions, where the auditioning musicians could be heard play, but not seen, by the judges, admitted significantly higher numbers of women than they had previously. Hawley's other example concerns how this kind of injustice can also take the form of attributing people's procedural knowledge to luck or instinct rather than actual knowledge. She considers a 1997 study which showed that women and non-white people had to "work

\footnotetext{
${ }^{8}$ It is tacit in the presentation of these ideas that they are intended to supplement the Frickerian account, being counted as kinds of epistemic injustice alongside testimonial and hermeneutical injustice.
} 
harder to prove that their performance is ability-based" (Hawley, 2011, 294), as opposed to based in instinct or luck.

Third, there is contributory injustice. In her 2012 paper A Cautionary Tale: On Limiting Epistemic Oppression, Kristie Dotson introduced “contributory injustice”, which refers to "an epistemic agent's situated ignorance, in the form of willful hermeneutical ignorance, in maintaining and utilizing structurally prejudiced hermeneutical resources that result in epistemic harm to the epistemic agency of a knower" (Dotson, 2012, 31). Unlike hermeneutical injustice, which refers to a single set of hermeneutical resources being obscured for all, contributory injustice occurs when marginalized groups have their own hermeneutical resources for understanding and expressing their own experiences, but instead of giving these resources uptake, non-marginalized groups wilfully continue to use their own dominant, biased hermeneutical resources to understand the marginalized group's experience.

Fourth, there is interpretive injustice. In his 2017 paper Epistemic Injustice in Utterance Interpretation, Andrew Peet introduced “interpretive injustice”. Interpretive injustice occurs when, owing to the same prejudicial stereotypes that lead to the assignment of credibility deficits, the hearer interprets the speaker uncharitably. Peet gives an example of a black man, who has been accused of raping a white woman, stating that his reason for being in her home was that she seemed "vulnerable", and being uncharitably taken to mean that he saw her as an easy target (as opposed to, say, because he wanted to help or protect her) (Peet, 2017, 3422). He also gives an example of a woman who refuses a man's sexual advances, which the man interprets as her being coy rather than actually expressing disinterest, and thus continues to pursue her (Peet, 2017, 3425).

Fifth, there is conceptual competence injustice. In her 2017 paper Conceptual Competence Injustice, Elizabeth Anderson introduced "conceptual competence injustice", in which a marginalized epistemic agent is unfairly taken not to have a proper grasp of the concepts that they are speaking about. Anderson gives the example of a woman of colour, who is a graduate student in philosophy, giving a presentation about philosophy of language. In it, she asserts that "natural kind terms are not rigid designators" (Anderson, 2017, 211). A white male undergraduate student takes her to have said something incorrect, as what she says goes against his understanding of 
Kripke, and as he is biased against women of colour (Anderson, 2017, 211). One might wonder, given this example, if conceptual competence injustice is any different from testimonial injustice. The difference, we can assume, is supposed to be that testimonial injustice involves prejudice leading the hearer to believe that the speaker is not giving reliable information, while conceptual competence injustice involves the hearer, owing to prejudice, believing the speaker specifically to not understand a particular concept that they are talking about. If Anderson's example is not persuasive of this difference, perhaps we could more convincingly illustrate the difference through a slightly different example: let's say that the undergraduate student takes what the graduate student is saying to be correct, but, because he is prejudiced against women of colour, thinks that the graduate student doesn't really understand what she is saying, and that she is just parroting what she has read or has been told, or is correct by chance, rather than that she genuinely understands the concepts in her talk.

Sixth, there is pragmatic competence injustice. In his 2018 paper Pragmatic Competence Injustice, Manuel Cruz introduced "pragmatic competence injustice", where a speaker or a hearer is deemed deviant or deficient in their communication skills, and taken to lack knowledge about how to communicate, owing to their way of speaking or comprehending being different from the dominant standard (Cruz, 2018, 151).

Alongside these papers that introduce new kinds of epistemic injustice intended to be included alongside testimonial and hermeneutical injustice, there are also papers that expand on the concepts of testimonial and hermeneutical injustice themselves, having them include a broader range of injustices. I will give examples of some of these papers below.

In his 2016 paper Testimonial Injustice and Prescriptive Credibility Deficits, Wade Munroe expands on Fricker's testimonial injustice, which she attributes to negative descriptive stereotypes, to include testimonial injustices that can be attributed to prescriptive stereotypes, based on empirical evidence that people who do not act in accordance with stereotypes are taken as less credible (Munroe, 2016, 924). He gives the example of a 1995 study, which demonstrated that women were seen as more "influential and persuasive" by men when they communicated in a "social style"-leaning toward the listener, having a friendly facial expression-whereas women who communicated 
in a "task-oriented manner"-speaking quickly and firmly, having a "taunt" (sic) posture-were seen as less influential and persuasive, and more threatening (Munroe, 2016, 935).

In his 2016 paper Testimonial Injustice Without Credibility Deficit, Federico Luzzi argues that testimonial injustice can exist without the assignment of a credibility deficit. He presents two types of testimonial injustice occurring without the assignment of a credibility deficit, which he calls "Type I" and "Type II". Type I refers to cases where one group of people believes that another group is being systematically "Gettiered" by some divine being. Because of this, the people in the first group take the people in the second group to be reliable sources of information, and believe that what the people in that group think is justified and true, but do not think that the people in that group actually know what they are asserting (Luzzi, 2016, 206). Type II refers to cases where what the members of one group says is taken to be true, but not doxastically justified-not formed or sustained with relevant considerations-by the other. As with Type I cases, speakers in Type II cases are taken to be reliable sources of information, but not taken to actually know what they are asserting (Luzzi, 2016, 207). Luzzi acknowledges that Type I cases are "far-fetched", but argues that there can be real-world examples of Type II cases, such as mansplaining, where a man explains to a woman why what she said is true as though she does not know (Luzzi, 2016, 208).

In her 2016 paper Typecasts, Tokens and Spokespersons, Emmalon Davis argues that testimonial injustices can occur owing to a credibility excess. She argues that there can be "identity-prejudicial credibility excesses", which occur when, owing to "benevolent" stereotypes such as Asian people being smart, or women being adept at housework, members of such groups are expected to be very knowledgeable about certain areas, and give testimony about their perceived area of expertise. She gives two examples: one of a woman in a grocery store who is approached by a man and asked where to find the dryer sheets. She explains that she does not work there, to which the man responds, baffled, “I know you don't work here, but you're a woman!" The second example is of an AsianAmerican student who, on the basis of his ethnicity, is approached by a group of white students to help them with a math problem (Davis, 2016, 487). 
From the get-go, the enumerative method has a significant setback: while it addresses the second gap in the Frickerian account (where we know that there are more kinds of epistemic injustice than just testimonial and hermeneutical injustice, but don't know what those other kinds of injustice look like), it doesn't address the first gap (that we don't know what the necessary and sufficient conditions of something being an epistemic injustice are). And without addressing the first gap, the account of epistemic injustice that we get from the enumerative method inherits the initial problem with the Frickerian account (a lack of necessary and sufficient conditions for something being an epistemic injustice), and, because of this, provides us with a list of epistemic injustices that is inelegant and somewhat arbitrary.

To elaborate, we can think of the Frickerian account as consisting of two parts. The first is the broad set up of the concept of epistemic injustice itself-what makes something an epistemic injustice-while the second is a list of the kinds of epistemic injustice. Neither part of the Frickerian account is complete. The first part is very ambiguous, and therefore doesn't provide us with the necessary and sufficient conditions of something being an epistemic injustice. The second part is incomplete, as though it seems to be the case that there are more kinds of epistemic injustice than just testimonial injustice and hermeneutical injustice, we aren't told what those other kinds are.

However, without knowing what makes something an epistemic injustice, it doesn't seem like we can say what other things are epistemic injustices alongside testimonial and hermeneutical injustices, so the ever-growing list of kinds of epistemic injustice that we get from the enumerative method seems arbitrary. To be fair, it seems like the enumerative method is working from a practical, observation-based way of looking at epistemic injustice, recognizing things that occur that seem reasonably like testimonial injustice or hermeneutical injustice; it would be uncharitable to present these things as being completely random. However, arbitrariness is still a problem, as unless we know what makes something an epistemic injustice, a resemblance to the things that were listed in the Frickerian account as being epistemic injustices seems like an unreliable way of identifying epistemic injustices.

At this point, one may object that I am assuming that we can only come to understand the concept of epistemic injustice via intension, and not considering extension as a valid 
method. While I think that there are times when extension can be useful, I think that the problem with using it to understand epistemic injustice is that in using this method, the concept of epistemic injustice can quickly become problematically broad and vague. Looking at the examples provided from the enumerative approach, I would argue that, while the basic interpretation of the Frickerian account is arguably too narrow, as it seems like epistemic injustice consists of more than just testimonial and hermeneutical injustice, the enumerative method leads to an account of epistemic injustice that is too broad, in that the epistemic aspect has stopped being of central importance. Within the list that has formed from the enumerative method, we have phenomena being labelled "epistemic injustice" that, rather than knowledge, focus on judgements of people's competence; skill; how normal their behaviour is; whether people are judged to be persuasive (rather than credible); and involve people being held in unusually high epistemic regard, but being pestered with requests to help people. Relating to this, there seems to be an absence of satisfying unifying factors across the types of supposed epistemic injustice that are being proposed. And so we have an arbitrariness problem.

Alongside arbitrariness, the enumerative method leads to an account of epistemic injustice that is inelegant, as it is an account that more or less consists of a long list of different kinds of epistemic injustice. While this alone would likely not be enough to conclude that the enumerative method is not the best method that we could be using, it is another point against a method that already has a significant setback.

As an alternative to the enumerative method, we have the pluralist method. In $A$ Cautionary Tale: On Limiting Epistemic Oppression, Dotson argued that having a single theory of epistemic injustice that can account for all kinds of epistemic injustice is an unrealistic goal given the pervasiveness of epistemic injustice, and how easy it is to commit. Instead of taking the enumerative approach and trying to amend the Frickerian account into one that successfully accounts for all kinds of epistemic injustice, Dotson suggests that we should treat the Frickerian account as an (rather than the) account of epistemic injustice, stating,

Instead of taking her [Fricker] to task about what she overlooks or what her account cannot track, we can simply acknowledge the strengths and limitations of her position and move on to offer another theory of epistemic injustice that 
addresses the limitations of her account. Accounts of epistemic injustice, then, can stand side by side, useful for different kinds of analyses in possibly compatible and incompatible sets of hermeneutical resources. (Dotson, 2012, 42)

This approach was echoed by Gaile Pohlhaus in her 2017 Varieties of Epistemic Injustice, in which Pohlhaus declines to offer "an exhaustive list of the varieties of epistemic injustice nor prescribe a definitive set of categories with which to classify them" (Pohlhaus, 2017, 14), and states that "we ought not consider any one approach to understanding epistemic injustice as foundational or definitive of all" (Pohlhaus, 2017, 16). The pluralist approach, then, involves accepting multiple different accounts of epistemic injustice, and treating each as highlighting an important aspect of epistemic injustice that other accounts may overlook or be unable to account for.

An advantage of the pluralist method is that it seems to both acknowledge and provide a solution for a problem that might come up in the formation of a single account of epistemic injustice. It is unlikely that any one person is going to be able to recognize or think of every possible kind of epistemic injustice, and thus, in any one account of epistemic injustice, it is likely that some important kinds of epistemic injustice are going to go unaccounted for, or even inadvertently necessarily excluded. On Pohlhaus's reading of the Frickerian account, for example, something that Pohlhaus thinks of as an important and pervasive kind of epistemic injustice-contributory injustice, where hermeneutical resources utilized by marginalized people to understand their own experience do not receive uptake by non-marginalized people, who choose to continue to use their own hermeneutical resources to interpret those marginalized people's experiences instead—cannot be counted as a kind of epistemic injustice, but instead has to be epistemic bad luck. ${ }^{9}$ Using the pluralist method, there is a way to overcome this problem: it removes individual responsibility to recognize all kinds of epistemic injustice, as, when each account is thought of as only one account of many, exclusions become less problematic, as different accounts are able to account for what is missing from one another.

\footnotetext{
9 I do not entirely agree with Pohlhaus's interpretation of epistemic bad luck here; however, the Frickerian account certainly does not explicitly recognize contributory injustice.
} 
However, the pluralist method still has significant shortcomings, facing similar difficulties to the enumerative method. While it doesn't necessarily inherit the problems with Fricker's account in the same way that the enumerative method does, as it explicitly recognizes that the Frickerian account has shortcomings and puts forward other accounts rather than trying to add to the Frickerian account, it doesn't solve the problem either, as the Frickerian account, without amendments, is still utilized, and while any of the other accounts of epistemic injustice that may be put forward might offer clearer necessary and sufficient conditions for something being an epistemic injustice, that account would only be accepted as a theory of epistemic injustice.

The pluralist method also has the same issue of inelegance as the enumerative method, in that under the pluralist method, we also end up with an ever-growing list, only where the enumerative method has a list of individual kinds of epistemic injustice under one theory, the pluralist method has a list of different theories of epistemic injustice.

A unique shortcoming that the pluralist method faces is that, as Dotson acknowledged, these different accounts may conflict with each other: one account may require that certain things not be counted as epistemic injustices, while another may require that those same things are counted as epistemic injustices. It seems that in such cases, the

pluralist method is meant to deal with this problem by claiming that both accounts are correct, and which one you should apply depends on what sort of analysis you are wanting to do. This, however, seems to give us a very weak and paradoxical understanding of epistemic injustice, in that epistemic injustice can at once be defined as both necessarily $\mathrm{x}$, and necessarily not $\mathrm{x}$.

The pluralist method, therefore, has enough setbacks that it also does not seem like the best method we could be using. Instead of utilizing either of these methods, I propose that we should instead come up with a new approach to understanding what epistemic injustice is.

\section{2: A New Approach}

Neither the enumerative approach nor the pluralist approach give us a satisfying account of epistemic injustice, and a new approach to understanding epistemic injustice 
is needed; in particular, one that deals with the issue that we don't have a set of necessary and sufficient conditions for something being an epistemic injustice.

There are two ways that I think we could approach this. One way is that we could take a "start over" approach, where we take the Frickerian account to be too problematic, and redefine epistemic injustice from scratch. However, this doesn't seem like the best approach to take, as in doing this we would be more or less just taking the term "epistemic injustice" and applying it to something entirely different, which would likely just be even more confusing given the degree of uptake that the Frickerian account has received.

Alternatively, and more appealingly, we could go back to the key ideas in the Frickerian account and try to clarify and fill in the gaps where important concepts are poorly defined and confusingly incorporated, and from this put together a set of necessary and sufficient requirements for something being an epistemic injustice. Note that this doesn't mean going back to Fricker's work and trying again to figure out how to interpret what she meant, but instead means looking back at the key concepts and providing an original, workable way of understanding and using them, considering both philosophical and practical values to create an account of epistemic injustice that is clear, elegant, and is able to be used to recognize real-world injustices.

Here, however, there is a possible objection to consider. Considering standpoint theory (very basically, that the knowledge one has depends on how one is situated), one may be concerned that no one account is going to be able to account for all kinds of epistemic injustice, as no one person is situated so as to recognize or think of all possible kinds of epistemic injustice. To this, I add that even if one account were able to account for all kinds of epistemic injustice, it would likely risk being inelegant and overly complex in order to cover so many different concepts.

In order to deal with this problem, we need to approach epistemic injustice in a different way. Up until this point, epistemic injustice has been thought of in quite narrow terms, with particular individual kinds of epistemic injustice, such as testimonial injustice or argumentative injustice, being identified. Problems of inelegance and oversight, I think, could be avoided if we instead started thinking more broadly, aiming to identify, rather 
than individual examples of epistemic injustice, broad categories into which those narrower kinds of epistemic injustice could fall. This would overcome both concerns: by thinking of broad categories, rather than individual examples, the chance of oversight is decreased, and we decrease inelegance, as we are able to have an account that accounts for narrower kinds of epistemic injustice without having to individually mention them all.

That being said, I am not claiming that the account I provide will definitely cover every possible kind of epistemic injustice, or provide the most elegant way possible of thinking about epistemic injustice. The following should more be taken as an example of the kind of direction that I think we should take in coming up with a functional account of epistemic injustice (identifying key basic concepts, providing necessary and sufficient conditions, aiming towards something both philosophically satisfying and practically useful, and thinking in terms of broad categories rather than specific examples), and remains open to future amendments. 


\section{Chapter Three: A New Account}

\section{0: Revisiting Key Concepts}

The first thing we need to do in building this account is to return to Fricker's key ideas about epistemic injustice, and explicitly identify what gaps need filling and clarifying. While these key ideas were discussed in Chapter Two, we should, for the sake of clarity, recap those ideas with fresh eyes, now looking towards explicitly identifying the key ideas in the Frickerian account, deciding how to define and use them, and turning them into an account of epistemic injustice that is both philosophically satisfying and practically useful. Let us begin by looking back to Fricker's introductory passage in Epistemic Injustice:

This book explores the idea that there is a distinctively epistemic kind of injustice. There are a number of phenomena that might be brought under the general head of epistemic injustice. Given how we normally think about justice in philosophy, the idea of epistemic injustice might first and foremost prompt thoughts about distributive unfairness in respect of epistemic goods such as information and education. In such cases we picture social agents who have an interest in various goods, some of them epistemic, and question whether everyone is getting their fair share. When epistemic injustice takes this form, there is nothing very distinctively epistemic about it, for it seems largely incidental that the good in question can be characterized as an epistemic good. By contrast, the project of this book is to home in on two forms of epistemic injustice that are distinctively epistemic in kind, theorizing them as consisting, most fundamentally, in a wrong done to someone specifically in their capacity as a knower. I call them testimonial injustice and hermeneutical injustice. (Fricker, 2007, 1)

The first idea to pull out of this passage is that epistemic injustice is something that is "distinctively epistemic", which Fricker puts some emphasis on: "This book explores the idea that there is a distinctively epistemic kind of injustice"; "When epistemic injustice takes this form, there is nothing very distinctively epistemic about it"; "By contrast, the 
project of this book is to home in on two forms of epistemic injustice that are distinctively epistemic in kind" (Fricker, 2007, 1).

The second idea to pull from this passage is of epistemic injustice being something that involves "a wrong done to someone specifically in their capacity as a knower" (Fricker, 2007, 1).

"Distinctively epistemic" has some positive and negative examples, while "a wrong done to someone specifically in their capacity as a knower" is used to describe the most important aspect of both testimonial and hermeneutical injustice, but neither is explicitly defined. Filling in these gaps, then, would be a good start.

Looking at Fricker's later work, we have some more key concepts to add in: distributive epistemic injustice, discriminatory epistemic injustice, and at least some forms of epistemic injustice being necessarily unintentional.

The key concepts in Fricker's account of epistemic injustice are:

1. Distinctively epistemic injustice

2. Incidentally epistemic injustice

3. Discriminatory epistemic injustice

4. Unintentionality in epistemic injustice

5. Distributive epistemic injustice

6. Wronged in one's capacity as a knower

Let us briefly expand on each idea, and each idea's relation to the others.

First, we have the idea of "distinctively epistemic" injustice, which Fricker presents in Epistemic Injustice as a very important concept, but then appears to downgrade the importance of it in later papers. What it means for something to be distinctively epistemic is never made clear, but it is tied to our second key idea: that something is not a distinctively epistemic injustice if it is "incidental" that the epistemic element of the injustice can be characterized as epistemic.

"Incidental" could be taken in two ways. One way we could interpret it is that it refers to importance, the other is that it refers to chance. Whether or not we need to understand which, however, depends on whether or not the concept of "distinctively 
epistemic" is still important. "Distinctively epistemic" may not be a concept that we need to understand as it may have been replaced by our next key idea, "discriminatory epistemic injustice”.

"Discriminatory epistemic injustice" refers to testimonial injustice, hermeneutical injustice, and other (unspecified) epistemic injustices that are not distributive. What makes discriminatory injustice discriminatory, and distributive injustices not discriminatory, is not clear, but Fricker emphasizes that discriminatory injustices must be unintentional.

By "unintentional", what is meant is that the perpetrator of the discriminatory epistemic injustice must genuinely take the victim to be lacking in credibility (in the case of testimonial injustice), or genuinely not have the concepts with which to understand the victim (in the case of hermeneutical injustice). They are still culpable, as they hold an unethical prejudice; however, they are not motivated by the prejudice to behave as though they don't believe or understand the victim, but rather are caused by the prejudice to make a genuine misjudgement of the speaker's credibility, or genuinely not understand the speaker.

Our next key idea, "distributive epistemic injustice", stands in contrast to discriminatory epistemic injustice, or to distinctively epistemic injustice, depending on whether one is looking at Epistemic Injustice, or one of Fricker's later papers. Drawing on Epistemic Injustice, distributive injustices are not a form of epistemic injustice as they are not "distinctively epistemic"; they are not "distinctively epistemic" because it is "incidental" that the good in question can be characterized as an epistemic good. Going off later papers, distributive injustices are a form of epistemic injustice, and are distinctively epistemic. "Distributive epistemic injustice" refers to the unfair/unequal distribution of epistemic goods such as education or information.

Fricker's final key idea is to be "wronged in one's capacity as a knower", which can be broken down into three concepts: "wronged”, "knower", and "capacity as a knower". In later papers, she appeared to expand on "wronged" to mean "insulted or undermined". "Knower" appears to be being defined by participating in the sharing or spread of 
knowledge or information. "Capacity as a knower" could therefore be taken to mean the ability to participate in the sharing or spread of knowledge or information.

Clearly, we need to figure out what to do with these concepts. We cannot use Fricker's account as is, as many of the key concepts of her account are tangled up and poorly defined. However, as discussed in Chapter Two, we should be clarifying and making use of the basic concepts that make up epistemic injustice. Let us discuss, then, how we could think of these concepts in a way which leads us towards some clear necessary and sufficient conditions for something being an epistemic injustice, in a way which is practically useful for identifying real-world epistemic injustices.

Let's begin with "a wrong done to someone specifically in their capacity as a knower." There are three key terms to deal with here: "wrong", "capacity (as a knower)", and "knower". I will discuss each of them in turn, beginning with "wrong".

\section{1: Wrongs}

In Epistemic Injustice, Fricker appeared to specify that epistemic injustice involves both an ethical wrong, and an epistemic error (Fricker, 2007, 22). Injustice without an ethical wrong, she notes, "would be a very weak sense of injustice; so much so that it is a mere shadow of our ordinary ethical and political sense of the word" (Fricker, 2007, 22).

To recap how "wrong" seems to be being defined in the Frickerian account, Fricker appears to elaborate on "wrong" in the second chapter of Epistemic Injustice, when she says that a certain act isn't an epistemic injustice as “...it does not undermine, insult, or otherwise withhold a proper respect for the speaker qua subject of knowledge" (Fricker, 2007, 20). "Wrong", then, can mean "to undermine, insult, or without a proper respect for" ${ }^{10}$ However, this still seems a little broad. What does it mean to undermine, insult, or withhold a proper respect for someone in their capacity as a knower? Here, there is a gap to be filled.

I think we should think of "wrong" as a two-pronged concept, based off of Fricker's "undermine, insult, or withhold proper respect for" idea. On one prong we have "insult,

\footnotetext{
${ }^{10}$ These are things that the perpetrator would be ethically culpable for, as opposed to things that the perpetrator inadvertently does as a result of innocent error.
} 
or otherwise withhold a proper respect for". This prong represents a recognition aspect. On the other prong, we have "undermine", which represents a practical aspect. This way, we can understand wronging someone in their capacity as a knower to take two forms: it can involve the perpetrator failing to properly recognize the victim's fulfilment of, or ability to fulfil, the capacities that they have as a knower, in such a way that is insulting or disrespectful; or it can involve the perpetrator preventing the victim from, or causing them to face unfair difficulty in, fulfilling the capacities that they have as a knower. By "perpetrator", I mean either an individual or a system. We need to go into greater detail about what each of these ways of wronging someone would look like, and I will do so in the next section. However, before we can do so, we need to talk about what is meant by "knower", and what someone's capacities as one are, as in order to robustly understand what it means to wrong someone in their capacity as a knower, we need to establish what a knower and what one's capacities as one are.

\section{2: Capacities and Knowers}

Let's consider how to define "knower".

In Epistemic Injustice, Fricker states "essentially what it is to be a knower is to participate in the sharing of information" (Fricker, 2007, 145). From this we can gather that she does not intend for "knower" to be interpreted in the obvious way as "someone who knows something", but instead is using it as more of a broad social concept, where the most important part of being a knower is participating in the sharing of information. Under what we might take to be Fricker's use of "knower", then, "knower" means "someone who participates in the sharing of information", and one's capacity as a knower is simply the capacity to participate in the sharing of information.

Fricker's focus on testimonial and hermeneutical injustice could lead us to think that Fricker's "sharing of information" refers particularly to giving information: her focus is on speakers who, owing to some wrong, find themselves unable to effectively pass information on to others. But it seems that here we can think more broadly than Fricker, and also include receiving information as an important part of participating in the sharing of information. After all, the sharing of information requires both a giver and a receiver of that information, and it seems that someone might, for example, be 
prejudiced against someone in such a way that they do not treat them as someone worthy of sharing information with.

However, I wonder if thinking of a "knower" as merely as someone who can participate in the sharing of information is really the best approach, as doing so only really enables us to think of epistemic injustice as being able to occur in contexts where someone either wants to inform someone of something, or to be informed of something by someone. A benefit to taking a broader definition of "knower" is that it aligns with the spirit of the contributions under the enumerative approach, underscoring the intuition that we do more as knowers than merely attempt to give information. In particular, alongside giving and receiving information, we should include in our notion of a knower the capacities to have knowledge, and to generate knowledge. I will elaborate on each in turn.

An agent could be wronged in their capacity to have knowledge in several ways. One way involves the perpetrator insulting the agent in their capacity as a knower by wrongfully not recognizing them to have the knowledge that they do. For example, a knower could have knowledge that they are not actively sharing with someonepossession of knowledge, without transmission of knowledge-and be insulted in their capacity to possess this knowledge via their having that knowledge not being recognized. Consider, for example, a prejudiced boss condescendingly over-explaining very basic things to a new employee, not recognizing that the new employee surely knows how to, say, open their emails, or operate the water cooler. Alternatively, an agent could be insulted in their capacity as a possessor of knowledge by not being recognized to have knowledge that they are actively sharing with someone. Consider something like “Type II" injustice, where a knower has knowledge that they are actively sharing, and are not prevented from sharing, but nonetheless fail to be recognized in actually possessing the knowledge that they are sharing. An example of this is a particular kind of "mansplaining", where a woman tells a man something, and the man proceeds to explain to her why what she said was correct, as he thinks that, while she is right, she doesn't really understand what she is saying, or have good reason for believing what she has asserted (Luzzi, 2016, 208). 
An agent could also be wronged in their capacity to have knowledge by being undermined in a way that prevents or causes them to face unfair difficulty in actually having knowledge. A knower could, for example, wrongfully be made to doubt their ability to correctly observe, interpret or understand scenarios or information, so as that they cease to believe, or face difficulty in believing, things that they were correct to believe. Consider, for example, gaslighting. ${ }^{11}$ Gaslighting works by "(inducing) in someone the sense that her reactions, perceptions, memories and/or beliefs are not just mistaken, but utterly without grounds - paradigmatically, so unfounded as to qualify as crazy" (Abramson, 2014, 2). A victim of gaslighting, then, could be prevented from, or made to face unfair difficulty in, having knowledge, as they would lose faith in their own ability to have knowledge.

Generating knowledge is also something that a knower could wrongfully not be recognized as, made to face unfair difficulty in, or be prevented from, doing. By "generating knowledge", I mean things like making discoveries and having original ideas. Here, a knower could be harmed by, for example, not being given credit for her discoveries or ideas-there is a long history of this happening to women in science, whose discoveries have been attributed to men-or by not being recognized in having the capacity to generate knowledge, and subsequently being prevented from generating knowledge, through, for example, stereotype threat. Stereotype threat of this sort occurs when people of a certain identity are stereotyped as not being people who have original ideas, and then internalize that stereotype, which thereby actually prevents them from having original ideas. A knower could also be made to face unfair difficulty in generating knowledge by unfairly not being given access to the resources to do so, as illustrated in Virginia Woolf's A Room of One's Own, where a woman at an educational institution is, unlike her male colleagues, not given access to a quiet space in which to work.

This broadening of the Frickerian account of what it means to be a "knower" brings us to how we should be defining "capacity as a knower". Building on this expansion, I think we can identify four main capacities that we have as knowers:

\footnotetext{
${ }^{11}$ Gaslighting would meet Fricker's standard of unintentionality so long as the gaslighter, owing to some prejudice, genuinely thought that the victim couldn't be trusted to, say, accurately remember or hear something; for an example of this kind of gaslighting, see McKinnon, 2017.
} 
1. The capacity to give knowledge

2. The capacity to receive knowledge

3. The capacity to possess knowledge

4. The capacity to generate knowledge

We can now understand what it means to be wronged in one's capacity as a knower much better: to wrongfully not be properly recognized in, or to wrongfully be prevented from or made to face unfair difficulty in, giving knowledge, receiving knowledge, possessing knowledge, or generating knowledge. We also have a way of using these concepts that allows us to recognize a broader range of epistemic injustices that are more reflective of our real-life social-epistemological activities than merely sharing information. However, we still need to discuss what is meant by "distinctively epistemic", and the role it plays in identifying epistemic injustices.

\section{3: Distinctiveness and Discrimination}

We should begin by recapping what we know about the concept of distinctively epistemic injustice. Fricker places some emphasis on Epistemic Injustice being a book that is going to discuss a kind of epistemic injustice that is "distinctively epistemic", referring to the idea three times in the introductory passage: "This book explores the idea that there is a distinctively epistemic kind of injustice"; "When epistemic injustice takes this form, there is nothing very distinctively epistemic about it"; "By contrast, the project of this book is to home in on two forms of epistemic injustice that are distinctively epistemic in kind" (Fricker, 2007, 1; emphasis added). However, Fricker later appeared to rescind this idea and change her emphasis from "distinctive" to "discriminatory", stating in Replies to Alcoff, Goldberg and Hookway on Epistemic Injustice:

[The concept of epistemic injustice] should be thought of as including distributive forms of epistemic injustice, such as unequal access to epistemic goods like information, or education. In this I agree with David Coady... who rightly affirms that distributive forms of epistemic injustice are, contrary to what I seem to say at the start of the book, distinctively epistemic injustices. It would 
have been better if I had placed the emphasis on my aim of unveiling forms of discrimination—epistemic discrimination... (Fricker, 2010, 175)

I think here it may be best to simply conclude that the Frickerian position on this point is uncertain and prone to change. However, this needn't be too much of an obstacle at this point, as at this stage we are not trying to interpret Fricker, but rather trying to get back to the basic ideas behind the concept of epistemic injustice, and fill in the gaps where key concepts were ambiguously, if at all, defined. I think what we need to know about the Frickerian perspective at this point is just that there is a distinction that is being drawn between injustices that involve the unfair distribution of epistemic goods, and injustices that are epistemic in a non-distributive way, and we need to know what to do with that distinction.

The first thing we need to decide is whether to look at this issue by maintaining the Epistemic Injustice approach and think of the distinction as being between distinctively epistemic injustice and distributive injustice, or to look at the issue using the later distinction between discriminatory injustice and distributive injustice. In Epistemic Injustice as Distributive Injustice, Coady challenges Fricker's distinction between discriminatory and distributive injustices, arguing that both testimonial and hermeneutical injustice, which are the kinds of injustice that Fricker gives as examples discriminatory injustice, can be "a form of distributive injustice (or at any rate can be fruitfully treated as such)" (Coady, 2017, 61). He argues that, in the case of testimonial injustice, credibility is finite, as it would be unreasonable to suggest that we believe all testimony, and that furthermore it is often a limited resource, as assigning a greater degree of credibility to one person can mean assigning a lesser degree of credibility to another, such as when the hearer has to choose which of two conflicting testimonies to believe (Coady, 2017, 63). Credibility, then, does fit a distributive model. In the case of hermeneutical injustice, Coady argues that "a particular substantive principle of just distribution is implicit in her (Fricker's) account of the phenomenon" (Coady, 2017, 64), as hermeneutical injustice occurs because of inequal access to being able to participate in the generation of social meanings. Hermeneutical injustice, Coady says, can be treated as "a form of injustice in the distribution of a certain good: namely hermeneutic power" (Coady, 2017, 66). Both concepts, then, actually fit a distributive model. 
Moreover, distributive injustices seem to be discriminatory in nature. Depriving certain people or groups of fair access to epistemic goods could reasonably be categorized as discriminatory, as such unfairness in distribution often also involves discriminating against those people or groups in particular. Certainly there could be cases where certain people or groups could be deprived of access to epistemic goods in a way which is non-discriminatory-random-but, things like testimonial and hermeneutical injustice, which Fricker characterizes as being discriminatory injustices, can also be random when they take a particularly incidental form. Intuitively, neither Fricker, nor anyone generally, would want to say that incidental testimonial or hermeneutical injustices are not discriminatory injustices because of this. I therefore do not think that this makes for a particularly strong objection, and the idea that distributive injustice at least often is discriminatory in nature still stands.

So, the discriminatory/distributive distinction is not a good one, as discriminatory injustices can be characterized as being distributive, and vice-versa. I would therefore suggest that we discard the discriminatory/distributive distinction. As the discriminatory/distributive distinction replaced the distinctive/distributive distinction, we should now turn back to the distinctive/distributive distinction, and discuss whether this is something that we should include in our new account.

In this case, understanding what makes distinctively epistemic injustices distinctively epistemic is particularly important, as in the Epistemic Injustice version of the Frickerian account, epistemic injustices that are non-distinctively epistemic seem like they are likely not counted as epistemic injustices. However, judging by more recent papers, it does seem like Fricker herself presently does not hold that distributive injustices cannot be distinctively epistemic, so perhaps we should be thinking less in terms of there being a distinction between distinctively epistemic injustices and distributive injustices, and instead think of an injustice being distinctively epistemic in nature as being a necessary requirement of something being an epistemic injustice, acknowledging that at least some distributive injustices can be distinctively epistemic.

In order to understand what it means for something to be "distinctively epistemic", however, we need to understand the concept of something being "incidentally" 
epistemic, as on the Frickerian account, distinctiveness was framed in contrast to incidental-ness.

\section{4: Incidentally Epistemic}

Fricker's Epistemic Injustice suggests that something is not distinctively epistemic if "it seems largely incidental that the good in question can be characterized as an epistemic good" (Fricker, 2007, 1). Distinctively epistemic injustice, then, is characterized by it not being incidental that the epistemic element of a potential epistemic injustice can be characterized as epistemic. But what is meant by "incidental"? Maybe it means something like "not important", or perhaps it means something like "by chance". In this section, I consider each in turn, concluding that we should interpret the word "incidental" to refer to something like "by chance".

Suppose we interpret the word "incidental" to refer to importance, e.g. how important it is that the epistemic element of a case is epistemic in nature. We could do this by assessing whether a case of potential epistemic injustice would be non-trivially changed (e.g. the case changes in a non-superficial way) if the epistemic element of the case were replaced with a non-epistemic element of similar value. ${ }^{12}$ If, by changing out the epistemic element for a non-epistemic one, the case does not non-trivially change, then it is incidental that the epistemic element can be characterized as epistemic. If the case does non-trivially change, then it is not incidental that the epistemic element can be characterized as epistemic, and the case is therefore one of distinctively epistemic injustice.

To illustrate, let's say that we were trying to decide if someone having their access to an educational resource taken away from them was a distinctively epistemic injustice. Consider the following example:

John wrongfully takes Mary’s books.

\footnotetext{
${ }^{12}$ It is important that the replacement is one of similar value, as if the epistemic element were replaced with a non-epistemic element of significantly different value, the case would obviously non-trivially change, but not in the way that we are trying to assess. There is, for example, a clear and important difference between, for example, depriving someone of an education, and depriving someone of air, but this doesn't tell us that education is importantly epistemic so much as it tells us that education is less valuable than breathing.
} 
Here, we would need to question if, if we took the epistemic element-books, being an educational resource-and replaced it with a non-epistemic element of similar value, the case would non-trivially change. So, let us compare the case "John wrongfully takes Mary's books" to an altered version of that case: "John wrongfully takes Mary's toys". Does the case non-trivially change?

The answer is unclear. It could be the case that it is important that what John is taking is books-something that Mary uses to learn-or it could be the case that it is unimportant that John is taking books and more important that John is wrongfully taking something from Mary, whatever that thing may be. And it seems to me that we could survey various people on whether there is a non-trivial distinction between the case "John wrongfully takes Mary's books" and "John wrongfully takes Mary's toys" and receive different answers from different people: distinctiveness as importance, at least with the degree of information that we are provided with in this example, is too much a matter of intuition.

Perhaps, then, we would be better to use the second form of "incidental", where "incidental" means "by chance". In this case, we need to question whether or not there is a clear reason that there is an epistemic element in the case, or if it is there by chance.

This sort of assessment is not one that we can do without more information, so let's flesh out the case of "John takes Mary's books" into two cases, the first where the epistemic element is epistemic by chance, and thus incidentally epistemic, and not an epistemic injustice; and the second where the epistemic element is not epistemic by chance, and thus distinctively epistemic, and is an epistemic injustice.

Case A: John and Mary live in a poor community, which consists primarily of two ethnic groups: $\mathrm{X}$ and $\mathrm{Y}$. Owing to their owning many of the shops in the community, members of ethnic group $\mathrm{Y}$ tend to be slightly financially better off than members of ethnic group $\mathrm{X}$, of which John is a part. $\mathrm{X}$ people hold a prejudice against $\mathrm{Y}$ people, believing them all to be greedy and getting rich off the backs of $\mathrm{X}$ people. Owing to this prejudice, it is commonly held among $\mathrm{X}$ people that it is acceptable to steal from Y people, as they deserve it. John, who holds this prejudice, breaks into the house of a Y person (Mary) and steals her 
books, as they were the thing that was closest to the window he climbed in, and small enough for him to carry.

Case B: John and Mary are relatives who live in a society where girls and women are strongly discouraged from reading or receiving an education, as it is seen as unfeminine for women to be educated, and a waste of time and resources when they should be concerning themselves with feminine duties such as cooking, cleaning, sewing, and looking after their children and male family members. John finds out that Mary has books in her possession, and thinks it shameful that a female relative of his is trying to educate herself, so he takes her books away so that she will be unable to continue to do so.

There is a clear difference between these two cases, even though each could be summed up as “John wrongfully takes Mary's books”. In Case A, it is more or less completely by chance that the injustice had an epistemic element, as John just wanted to steal something from Mary, and books happened to be the thing he had the easiest access to. Had there been something else in Mary's house that had been as easy in size and location to steal as the books, John would have been equally as likely to steal that instead. In Case B, however, it is not at all by chance that the injustice had an epistemic element, as John took the books from Mary precisely because they were an epistemic good, and because he wanted her to be harmed epistemically: he desired that she be prevented from learning. It therefore seems right to characterize Case A not as an epistemic injustice but as an injustice of some other sort, and to characterize Case B as an epistemic injustice.

At this point, we might be concerned that these examples seem too different from Fricker's original examples of epistemic goods, as a book is a material object, while information and education are not. However, this needn't be a problem. I think that when we talk about the unfair distribution of epistemic goods, material goods like books are something that haven't yet been considered, and should be, and we now have a way to think about them. Further, thinking about distinctiveness as meaning "not by chance" can usefully carry over to the immaterial epistemic goods that Fricker discussed. Consider the following cases, which the below sentence could describe: 
Mary tells everyone in the office, except for John, some important information.

Case A: Mary holds a prejudice against John, and, owing to this, avoids talking to him under any circumstance. It makes no difference to Mary whether she is passing on important information, or simply wishing the team a happy weekend. John is simply someone that she will not talk to.

Case B: Mary holds a prejudice against John, and, owing to this, decides to attempt to sabotage him by not giving him important information.

In Case A, it is by chance that John was not given important information (an epistemic good): Mary would have avoided communicating with him regardless of if she was giving everyone important information, or she was merely wishing the team a happy weekend. In Case B, it is not by chance that John is not given important information (an epistemic good), as Mary was deliberately depriving the victim of that epistemic good specifically.

Thinking of distinctiveness in terms of chance seems like a better way to think than in terms of importance, as the difference between something being epistemic by chance, and something being epistemic not by chance, is more obvious and less up for interpretation than if we think of distinctiveness as importance. An injustice is distinctively epistemic, then, if it is not by chance that the epistemic element is epistemic.

\section{5: Intentions and Experiences}

We can now think of epistemic injustice as someone being insulted (wrongfully not given adequate recognition or respect in their ability to fulfil, or in their active fulfilling, of their capacities as a knower) or undermined (wrongfully prevented from, or made to face unfair difficulty in, fulfilling their capacities as a knower) in their capacities as a knower (giving knowledge, receiving knowledge, possessing knowledge, generating knowledge) in a way which is distinctively epistemic (where the epistemic element of the case is not epistemic by chance). We have rejected understanding epistemic injustice as being divided along discriminatory vs. distributive lines, as the distinction seems weak. We have also rejected thinking of epistemic injustice as being divided along 
distinctive vs distributive lines, as some distributive injustices can be distinctively epistemic.

However, now our account of epistemic injustice faces a problem: for Fricker, epistemic injustices are also unintentional (though still something that the perpetrator is ethically culpable for), a concept we have been ignoring until now. Fricker only explicitly applied this requirement to discriminatory injustices, but since we eliminated discriminatory injustices as a category, perhaps we should think of all epistemic injustices as being unintentional. If this is so, then our cases of distinctively epistemic injustice end up not being epistemic injustices, as they are certainly intentional.

Here, we may have to reject this element of Fricker's account in favour of including some intentional injustices as epistemic injustices. There are two main reasons for doing this, which I will address in turn:

1. Requiring that epistemic injustice not be intentional requires that we need more information than we will in many cases have access to in order to diagnose something as being an epistemic injustice.

2. Requiring that epistemic injustice not be intentional places too much focus on the experience of a perpetrator of the injustice and too little focus on the experience of the victim of the injustice.

Let's consider the first point. On the Frickerian account, for something to be an epistemic injustice, it requires that the perpetrator make a genuine error stemming from prejudice. In that case, the hearer must genuinely hold a prejudice that has genuinely clouded their vision, which in turn has caused them to make a genuine mistake (for which, nonetheless, they are ethically culpable, owing to their prejudice). This requires us to have a lot of information about the perpetrator's mental states in order to be able to diagnose something as an epistemic injustice.

This may seem like a problem that goes beyond the scope of what we should care about: while we may only rarely have access to this kind of information, there is still a fact of the matter, maintaining this requirement, about whether or not something is an epistemic injustice. Philosophically speaking, then, we may not have a problem. However, epistemic injustice is not just a philosophical concept, it is also a practical and 
social one, serving to diagnose a real-world problem. For this reason, we should care about the problem of having to know the perpetrator's mental states. After all, if it turns out that we can't actually apply the concept of epistemic injustice in the real world because in the real world we don't have enough information, the concept of epistemic injustice is practically useless.

It is not the case that we never have access to the kind of information that the Frickerian account requires. Fricker herself offers several examples of epistemic injustice from novels, which give us the freedom to unproblematically attribute whatever mental states to the characters that we see fit-for example, the jurors in To Kill A Mockingbird, where she requests that we interpret the text in such a way that we conclude that the jurors genuinely believe that Tom is guilty (Fricker, 2007, 25). As the analysis is of a fictional case, this insistence that we interpret what the jurors were thinking one way and not consider other options, such as, say, that the jurors know that Tom did not commit the crime that he has been accused of, but are motivated by their racist hatred to convict him anyway, is not significantly problematic. But if this were an analysis of a real-life case, it would be both epistemically and ethically problematic to suggest that we must interpret what was going on in the juror's minds a certain way so that we can call what happened an epistemic injustice. Alternatively, when looking at examples from fiction, we may have access to a character's mental states via the narrator informing us of their true motivations. Fictional examples, therefore, are often easy and unproblematic cases in which we can have adequate information about the perpetrator's mental states to diagnose something as an epistemic injustice. Fictional examples can be useful when it comes to illustrating what certain kinds of epistemic injustice look like. However, the kind of information we can have in fictional examples is not often the kind of information we have access to when it comes to diagnosing epistemic injustices in real life.

Of course, it is not that we never have access to this information in real life. In some cases, the perpetrator may explicitly state, or otherwise make very obvious, that they are genuinely taking someone to be, say, less credible than they ought to because of some prejudice that they hold. However, there are likely many instances where a person feels that they are being insulted or undermined in their capacity as a knower, but no 
one but the perpetrator would be able to say for sure whether they are, for example, genuinely taking the victim to be non-credible, or if they are merely treating the victim as though they are non-credible. Requiring that epistemic injustices be unintentional, then, often requires us to be mind-readers in order to be able to diagnose them, which is practically problematic.

This brings us to our second point: requiring that epistemic injustices be unintentional places too much focus on the mental states of the perpetrator, and too little focus on the experience of the victim. To illustrate, consider a case where someone is insulted and undermined as a receiver of information.

Let's say that Annie is a female student in a high school Physical Education class which is taught by a male teacher, Mr Mark. Let us also stipulate that Annie and Mr Mark live in a society where sports are seen as a male interest and pastime, which females aren't really capable of fully appreciating or understanding. Whenever Annie asks Mr Mark questions in class, he doesn't bother answering her properly, usually giving some very vague answer or simply saying that it is too complicated for Annie to understand.

Here, we could interpret Mr Mark's intentions in two ways. Maybe he is sexist, and, owing to this prejudice, genuinely does not believe that it is worth trying to answer Annie's sports-related questions because he genuinely thinks that, because Annie is a girl, she wouldn't be capable of understand the answers. Alternatively, maybe Mr Mark is just lazy and can't be bothered answering Annie's questions as doing so would take more time and effort than he can be bothered expending, so he chooses to behave as though he doesn't think that Annie could understand so that he doesn't have to answer her.

However, it doesn't make a difference for Annie whether or not Mr Mark genuinely thinks she is incapable of understanding sport, or if Mr Mark is choosing to behave as though he thinks that she is incapable of understanding sport. The harm she suffers is the same either way: she is still undermined in her capacity as a receiver of information. By requiring that epistemic injustice is unintentional, we fail to recognize, or place adequate importance on, this fact. That is not to say that we should place no importance on the perpetrator's motivations. However, if someone is being insulted or undermined 
in their capacity as a knower, exactly why that is happening doesn't seem like a detail upon which we should hinge whether or not they are actually experiencing an epistemic injustice.

Let us now return to the concept "distinctively epistemic". Earlier, we concluded that being "distinctively epistemic" involved it not being by chance that the injustice in question had an epistemic element. We identified a relevant difference between books being taken from someone in a robbery, and books being taken from someone in order to prevent them from being able to get an education. We can now ask, does requiring that an injustice be distinctively epistemic face the same or similar issues as requiring that an injustice be unintentional does? Much like requiring that an injustice be unintentional, requiring that an injustice be distinctively epistemic means that we have to have access to the motivations of the perpetrator, and it discounts the experience of the victim. In the book example, if books are an important source of education and information to a person, having those books taken from them, even just in a case of theft, harms that person epistemically. It seems, then, that if we are going to eliminate unintentionality as a necessary condition of epistemic injustice, we should also eliminate the injustice being distinctively epistemic as a necessary condition of epistemic injustice.

However, it does seem like there is some kind of important difference between cases of epistemic injustice where the injustice is intentional and when it is not, and between cases of epistemic injustice where the epistemic element is by chance and when it is not. I will discuss what to make of this in the next section.

\section{6: Epistemic Purity}

As noted in the previous section, we should eliminate the requirement that epistemic injustices must be unintentional, and distinctively epistemic. But, it doesn't seem right to infer that the concepts of unintentionality and being distinctively epistemic have no importance: cases where the injustice is unintentional seem importantly different to those where it is intentional, and the same is true with distinctively epistemic and nondistinctively epistemic cases. 
A solution is to instead of treating unintentionality and distinctive epistemic-ness as necessary conditions of epistemic injustice, use them to diagnose what I will call the "epistemic purity" of an epistemic injustice, by which I mean the extent to which an injustice is epistemic in nature.

Cases where the epistemic injustice is unintentional have a higher degree of epistemic purity, because someone is wronged in his or her capacity as a knower by someone who genuinely misjudges his or her epistemic capacities, and in doing so not only epistemically wrongs that person, but also makes an epistemic error. By contrast, cases where the epistemic injustice is intentional have a lower degree of epistemic purity, because someone is wronged in his or her capacity as a knower, but the perpetrator does not genuinely misjudge the victim's epistemic capacities, so there is no epistemic error, but rather intentional unethical behaviour.

Similarly, cases where the epistemic injustice is distinctively epistemic have a higher degree of epistemic purity, as it is not by chance that there is an epistemic element to the case. By contrast, cases where the epistemic injustice is not distinctively epistemic have a lower degree of epistemic purity, as while there is an epistemic element to the case, there could, just as easily, not have been an epistemic element to the case, and it was by chance that there did happen to be one.

While we are not using epistemic purity as a condition of epistemic injustice, the concept of epistemic purity could be useful when it comes to thinking about how to address the problem of epistemic injustice. While how to overcome epistemic injustice is not the topic of this thesis, having a sense of epistemic purity may be useful when it comes to overcoming epistemic injustices, as it may be helpful to know whether the solution for any given epistemic injustice needs only to address epistemic injustices, or if there are other kinds of injustice present in the case that also need to be focused on, sometimes perhaps even more so than the epistemic injustice itself. To appreciate this, let's return to the "John wrongfully takes Mary's books" case. If we look at the nondistinctively epistemic form, where John steals Mary's books because he wanted to steal something, and the books just so happened to be the easiest thing for him to steal owing to their size and location, it seems like there is a theft problem that needs to be targeted as much, if not more so, than an epistemic injustice problem. Likewise, looking back to 
the "Mr Mark won't answer Annie's questions" case, if we look at the incidentally epistemic form, where Mr Mark isn't answering Annie's questions because he is lazy, it seems like there is a teacher laziness problem that needs to be targeted as much, if not more so, than an epistemic injustice problem.

As overcoming epistemic injustice is not the topic of this thesis, I will leave the concept of epistemic purity in this fairly basic form without exploring or developing the idea further. However, I hope it is a useful suggestion both in terms of thinking about ways of overcoming epistemic injustices, and thinking about how to put the concepts of intentions and distinctiveness to use without using them as necessary conditions of something being an epistemic injustice, as the distinctions that they marked did seem important.

\section{7: Context and Harm}

At this point, our new account of epistemic injustice is that epistemic injustice necessarily involves one being insulted (wrongfully not being given adequate recognition or respect in one's ability to fulfil, or in one's active fulfilling, of one's capacities as a knower) or undermined (wrongfully being prevented from, or made to face unfair difficulty in, fulfilling one's capacities as a knower), in one's capacities as a knower (giving knowledge, receiving knowledge, having knowledge, generating knowledge). We have eliminated unintentionality and being distinctively epistemic as necessary conditions for epistemic injustice.

This account, however, faces a possible objection. As discussed in Chapter One, in Epistemic Injustice and Evolving Concepts of Epistemic Injustice, epistemic injustice was presented by Fricker as something that the perpetrator must be ethically culpable for, and involve epistemic error, e.g. the genuine misjudgement of the speaker's credibility, or a genuine inability to understand the speaker's experience. On our new account, we have eliminated the requirement that the perpetrator must make an epistemic error, allowing for cases where the perpetrator does not actually misjudge the victim's capacities as a knower, i.e. intentional epistemic injustice. 
On the Frickerian account, only one sort of intentional epistemic injustice is discussed. ${ }^{13}$ In this kind of intentional epistemic injustice, the perpetrator of the injustice intentionally manipulates the situation (e.g. she pretends not to believe or understand the speaker) so that the victim is harmed epistemically, even though the perpetrator does not actually misjudge the credibility of, or does not actually not understand, the victim. However, this may not be the only form of injustice that involves ethical culpability-wrongfully insulting or undermining someone in their capacity as a knower-without epistemic error worth considering. Intentionally manipulating the situation in the way that Fricker suggests is certainly one way that a perpetrator could be ethically culpable, but, there may be a broader range of wrongs that a perpetrator could commit that harm their victim epistemically.

Consider, for example, if I were driving very recklessly with a passenger in my car, and, as a result of my reckless driving, ended up crashing. Let's say that in this crash, my passenger is badly injured, and ends up with brain damage, which causes them to face great difficulty across many epistemic activities.

Here, I have done something for which I am ethically culpable. I have driven recklessly, and as a result of my doing so, my passenger is epistemically harmed: she is undermined in her capacity as a knower, as she is prevented from, or made to face unfair difficulty in giving, receiving, possessing and generating knowledge. This may serve as a counterexample to our new account of epistemic injustice, in that if something is an epistemic injustice even if the perpetrator does not make an epistemic error, then it seems like we have to say that in getting into a car crash, I have committed an epistemic injustice against my passenger, as, because of something that I am ethically culpable for, my passenger is undermined in her capacity as a knower. And that seems intuitively wrong. Getting into a car crash just doesn't feel like the kind of thing that we should be diagnosing as an epistemic injustice, as it doesn't directly involve me viewing or treating, or wrongfully not viewing or not treating, my passenger as a knower. ${ }^{14}$

\footnotetext{
${ }^{13}$ Note Fricker does not appear to count these injustices as epistemic injustices.

${ }^{14}$ One could argue that my reckless driving was the result of me wrongfully not viewing my passenger as a knower and therefore not considering the harm to her capacities as a knower that my reckless driving could incur; for the sake of simplicity let's assume that I did view my passenger as a knower, but wasn't
} 
We could avoid this problem by introducing the concept of what I will call "epistemic context" as a necessary condition of epistemic injustice. By "epistemic context", I mean a context in which someone being viewed or treated (or wrongfully not viewed or not treated) as a knower is relevant to the situation. A case where I cause someone brain damage by driving recklessly and crashing is not an epistemic injustice, even though it ultimately harms my passenger epistemically, as it did not occur in an epistemic context. Introducing epistemic context also means that cases such as the book theft case also do not qualify as epistemic injustices: while stealing Mary's books may have harmed her epistemically, a robbery of the sort described would not qualify as an epistemic context. Here, we have a clarification to make in terms of the necessary and sufficient conditions for an epistemic injustice: both epistemic context and epistemic wrong (being insulted or undermined in one's capacity as a knower) are necessary conditions for an epistemic injustice. However, neither alone is sufficient: both must be present in order for an epistemic injustice to have occurred. Jointly, they are sufficient.

The car crash and the book theft examples show what a case looks like where an epistemic wrong occurs outside of an epistemic context. Such cases tend to be intuitively recognizable as not being epistemic injustices: they simply don't seem like the right kind of thing. However, cases where a non-epistemic wrong occurs inside of an epistemic context perhaps aren't as intuitively not epistemic injustices. This is illustrated by the inclusion of these kinds of cases in other papers suggesting new kinds of epistemic injustice.

For example, consider epistemic exploitation. Epistemic exploitation involves "unrecognized, uncompensated, emotionally taxing, coerced epistemic labor" (Berenstain, 2016, 570). It might most simply be characterized by marginalized people being expected to do epistemic labour for privileged people, taking on the role of educating them, often without compensation for their time and effort, and often at the cost of their emotional wellbeing. Clearly, epistemic exploitation occurs in an epistemic 
context. However, it in itself does not involve an epistemic wrong, despite certainly being harmful in other ways.

To illustrate, let us consider the following example of epistemic exploitation.

A professor, who is part of a racial minority, is expected by his colleagues to be on panels to increase diversity and educate others, and is frequently approached by his colleagues with questions about racial issues in academia and how best to supervise and teach their non-white students. The professor finds this extra labour tiring and emotionally taxing, and is not paid for the extra hours he spends educating and coaching those around him.

Clearly, something unjust is going on here. The professor is expected to do more (uncompensated, emotionally taxing) work than his colleagues, and, while he is perhaps technically free to refuse to do so, he is likely to face consequences should he fail to meet those expectations. Refusal to be on panels or to answer his colleagues' questions would mean risking being seen as difficult, touchy, unhelpful, or even ungrateful that his department is making an effort to become educated on racial matters, which would come with social and professional consequences for the professor. And clearly, this injustice is occurring in an epistemic context, where giving and receiving knowledge is centrally at play.

However, it would be wrong to characterize epistemic exploitation as an epistemic injustice, as the professor is not insulted or undermined in his capacity as a knower. The professor is recognized to have knowledge, and is given the opportunity to share that knowledge. He is wronged, certainly, but he is wronged through unreasonable expectations of labour and being underpaid for the hours he puts in, not by being insulted or undermined in his capacity as a knower. This is not to in any way imply that the injustice the professor suffers is any less serious than an epistemic injustice. However, characterizing it as an epistemic injustice would be incorrect.

Here, one may object that this is a case that should motivate us to expand our notion of epistemic injustice so that alongside being insulted or undermined, we include being unfairly epistemically burdened as a way in which one might be wronged as a knower. There are two ways I would respond to this. Firstly, epistemic burdening is different 
enough from being insulted or undermined as a knower that we should be dissuaded from making this change to our notion of epistemic injustice, or at least approach such a change with hesitation. Being insulted and being undermined as a knower are both negative in nature: they ultimately concern someone not being recognized as a knower, or someone being prevented from (or made to face unfair difficulty in) exercising their capacities as a knower. Epistemic burdening, meanwhile, is positive in nature, ultimately concerning someone being encouraged or expected to do something. Secondly, epistemic burdening is something that we can understand without needing to invoke a new concept (epistemic injustice). Unfair or unreasonable expectations of non-manual labour is something that we already understand: consider, for example, the phenomenon of women being expected to do a disproportionate amount of emotional labour compared to men. Perhaps, if we think of how similar various kinds of injustice are to one another, epistemic burdening is an injustice that falls close to epistemic injustice, and therefore there could be reasons for considering them alongside each other. However, I am not convinced that we should consider epistemic burdening to be an actual epistemic injustice.

It is worth noting that some examples of epistemic exploitation have been put forward that would meet our conditions for being an epistemic injustice. For example, Berenstain gives the example of Summer, a female graduate student, having to explain to Dean, a male graduate student, why it was sexist of their department, which has a culture of misogynistic behaviour, to award all of their fellowship positions to males. Dean dismisses her, denying that the department as a whole has a culture of sexism and putting the blame on "a few bad apples" (Berenstain, 2016, 582), and telling Summer that the fellowships were awarded on meritocratic principles and that she must be making up and blaming sexism rather than facing up to her own shortcomings. But this example is not of epistemic exploitation alone: it is epistemic exploitation (a male student expecting a female student to educate him about the sexist culture of their department) followed by testimonial injustice, when he doesn't take her as a credible source.

A similar concept can be found in identity-prejudicial credibility excess, which occurs where, owing to stereotypes, a credibility excess is assigned to an agent to their 
detriment. Two examples of this are given in Davis's Typecasts, Tokens, and Spokespersons (2016). The first example is of a woman who is approached by a man in a store and asked where to find the dryer sheets. She tells him that she doesn't know and that she doesn't work there, to which the man responds, baffled, that he knows that she doesn't work there, but thought she'd know because she's a woman. Here, the man is stereotyping her, owing to her being a woman, as someone who does the laundry and/or does the shopping for laundry products in her household, and is attributing an excess of credibility to her in light of this: he is assuming that she knows as least as much as an actual employee of the store about where to find the dryer sheets, and is confused when he learns that she doesn't. The second example is of an Asian-American student who is approached by a group of students at school who want help with a math problem, who assume that because the student is Asian, the student is good at math, leaning on the stereotype of Asian people as being mathematically skilled and attributing an excess of credibility to the student as a result (Davis, 2016, 487).

What is occurring with identity-prejudicial credibility excesses (which I will refer to from here onwards as "IPCEs") seems on the surface to be very similar to what is occurring with epistemic exploitation: someone is assumed to have knowledge about something, and he or she is expected to share this knowledge with someone else. Much like epistemic exploitation, IPCEs don't seem to involve someone being wronged epistemically, as they are not insulted or undermined in their capacity as a knower; rather, they are taken to be very credible, and they are given ample opportunity to share their knowledge.

However, there might be more to say about IPCE than there is to say about epistemic exploitation, as there seems to be something a bit more epistemically and ethically complicated going on. Both IPCE and epistemic exploitation deal with what I will call "special knowledge"; that is, knowledge that one has access to because of their identity. However, while epistemic exploitation deals with what I will call "genuine special knowledge"-knowledge that someone actually does have access to because of their identity-IPCEs deal with what I will call "pseudo special knowledge"-knowledge that identity has little to do with, but is treated as special knowledge because of stereotypes. Looking back at our professor example, the professor genuinely does have special 
knowledge about matters relating to departmental treatment and lived experiences of people of his ethnicity, because he is of that ethnicity and he has those experiences. However, being a woman does not give one special access to knowledge about where to find cleaning items in a store, and being of Asian descent does not give one special access to knowledge about math.

IPCEs are therefore wrongful in a way that issues concerning genuine special knowledge are not, in two ways. Firstly, IPCEs involve incorrectly and insultingly attributing a person's knowledge to that person's identity, rather than treating that person as an individual. Davis described the wrong of IPCEs in part as treating members of the same identity group as though they were interchangeable (Davis, 2016, 487-488). However, I would characterize the wrong more specifically as the attribution of knowledge to a person's identity instead of attributing that knowledge to the individual having some positive attribute such as intelligence, being observant, or being a hard worker. Secondly, it seems likely that IPCEs, like most injustices, will often be targeted at marginalized people. In light of this, the sort of knowledge that is attributed to a person because of an IPCE seems likely to not be the kind of knowledge that is particularly valued. Some evidence for this could be taken from how respected or highly paid a profession becomes in accordance with a change in what kinds of people make up a majority of the profession. For example, the Aeon article The Woman Subject discusses how the wage and perception of the teaching profession changed as more women became teachers:

In public schools in the US, 77 per cent of teachers are identified as women, a feminisation of the profession that Bhattacharya says began in 1900 and might have started because teachers' salaries began to decline as the school year lengthened. But with feminisation came a 'deskilling' of teaching as less a profession than a continuation of stereotypically female care work. Teaching along with nursing and childcare can be paid poorly because the care work it exemplifies is supposed to be something that women do naturally, from birth. The same presumably holds for housekeeping and similar minimum-wage jobs that keep many in poverty. In short, conventional ideas of the innate biological 
capacities belonging to women and men remain structurally embedded in significant institutions and practices. (Warnke, 2019)

Work that is seen as "women's work", it seems, is not highly valued. By extension, we may assume that the knowledge that is involved in being able to do women's work is not highly valued. And work that comes to be seen, or has always been seen, as women's work, involves knowledge that women are stereotyped to have because they are women. Should this make IPCE an epistemic injustice, where epistemic exploitation is not? I am not sure that there is an easy answer. My tentative suggestion would be that we should perhaps count some IPCEs as something at least related to epistemic injustice. However, in order to be more certain about this, I think we would need to have more than speculation in the way of how the knowledge that is attributed via IPCEs is valued. If it could be shown that the kind of knowledge that is attributed via IPCEs is generally not valued, and that as a result, the capacities as knowers that the targets of IPCES have are underestimated, I think there would be a case for calling IPCEs epistemic injustices, as this would perhaps involve victims of IPCEs being insulted in their capacities as knowers. For now, however, I will simply note that this could be an interesting point for further exploration.

To sum up, given the stage that our new account was in at the beginning of this section, there was a risk of our new account being backed into having to call injustices that intuitively are not epistemic injustices, epistemic injustices. To overcome this issue, I introduced the necessary requirement of "epistemic context". From here, we discussed how both epistemic harm (being wronged in one's capacity as a knower) and epistemic context must both be present in order for an injustice to qualify as being an epistemic injustice.

\section{8: The New Account}

My goal across this section has been to work from the key concepts in the Frickerian account to construct an account of epistemic injustice that, unlike the Frickerian account itself, is both philosophically satisfying and practically useful, without totally eliminating the thinking behind the Frickerian account and other authors' 
contributions. I am now able to present that account. First, I will briefly outline the Frickerian account, and the problems that I identified with it. Second, I will give an overview of the enumerative and pluralist method, and their corresponding problems. Finally, I will give my new account of epistemic injustice, and compare it to the Frickerian account, and to the enumerative and pluralist methods of thinking beyond the Frickerian account, and highlight how my new account overcomes the problems that I identified both with the Frickerian account and the enumerative and pluralist methods.

Let's start by looking at the Frickerian account. On the Frickerian account, it seems like epistemic injustice is something that is distinctively epistemic (what this means was left unclear) and involves the victim being wronged in their capacity as a knower (what this means was also left unclear). Epistemic injustice must be unintentional, and be owing to something that the perpetrator is ethically culpable for, and involve the perpetrator making an epistemic error. Epistemic injustice breaks down into (at least) two different kinds: testimonial injustice, and hermeneutical injustice.

I identified the following main problems with the Frickerian account that prompted the need for a new one. Firstly, it is ambiguous. Key terms are left undefined, and the way that the concepts fit together is unclear. Secondly, it does not provide us with a set of necessary and sufficient conditions for something being an epistemic injustice, which makes identifying epistemic injustices outside of testimonial injustice and hermeneutical injustice, which Fricker explicitly identified, a difficult task to carry out in a philosophically satisfactory way which avoids arbitrariness. Finally, it does not allow us to reliably identify epistemic injustices in real life, as it requires us to have more information about the mental states of the victim than we are likely to often have.

Now, let's look at the two methods of progressing past the Frickerian account of epistemic injustice. First, there is the enumerative method, which involves adding new kinds of epistemic injustice alongside testimonial and hermeneutical injustice, so that epistemic injustice comes to be understood primarily as a list of different kinds of injustice. As the enumerative method does not involve recognizing and addressing the ambiguity and lack of necessary and sufficient conditions of something being an epistemic injustice provided in the Frickerian account, it inherits these same problems, 
and the additional kinds of epistemic injustice introduced in this method resultingly seem arbitrary, and form an inelegant list. Second, there is the pluralist method, which involves thinking of the Frickerian account as one account of epistemic injustice that can stand alongside others. The pluralist method also has problems of inelegance, and while it does not necessarily inherit the Frickerian account's problems in the way that the enumerative approach does, it also doesn't solve them, as the Frickerian account continues to be used. Alongside this, the pluralist method results in a weak and paradoxical understanding of epistemic injustice, in that, as different accounts may conflict with one another, we could have a situation where we have to understand epistemic injustice as at once necessarily something, and necessarily not that same thing.

My new account of epistemic injustice is as follows: epistemic injustice occurs when someone is wrongfully (in a way in which the perpetrator is ethically culpable) insulted and/or undermined in their capacities as a knower, in an epistemic context.

To break this down, one's capacities as a knower are to give, receive, possess, and generate knowledge. One is insulted in these capacities if one is not recognized or respected in one's fulfilling, or ability to fulfil, one or more of these capacities. One is undermined in these capacities if one is prevented from, or made to face unfair difficulty in, fulfilling one or more of these capacities. An epistemic context is a context in which someone being viewed or treated (or wrongfully not viewed or not treated) as a knower is relevant to the situation. A perpetrator is ethically culpable for the insulting or undermining of someone in their capacity as a knower if the perpetrator insults or undermines him or her by doing something ethically problematic for which they are responsible, as opposed to making an innocent mistake.

This new account overcomes the problems that I identified with the Frickerian account, while avoiding the pitfalls I identified with the enumerative method and the pluralist method. While it works with some of the key concepts in the Frickerian account, it assigns meaning to those terms, which the Frickerian account did not, or only did vaguely. It therefore overcomes the ambiguity problem. The new account also provides a clear set of necessary and sufficient requirements for something being an epistemic injustice: in order for an epistemic injustice to have occurred, someone must be insulted 
and/or undermined in one or more of his or her capacities as a knower, in an epistemic context, by a perpetrator who is ethically culpable for this insulting/undermining. This allows us to be able to identify new epistemic injustices, as they would fall into these broad categories of epistemic capacities and wrongs, without our account having to explicitly list of every kind of epistemic injustice. While the Frickerian account required that the perpetrator of an epistemic injustice be both ethically culpable and make an epistemic error, which made epistemic injustices difficult to reliably identify in real life (where we would likely not have access to that information), the new account eliminates the requirement that the perpetrator make an epistemic error. This makes epistemic injustices easier to identify in real life, as we do not need to know if the perpetrator of the injustice genuinely misjudges the epistemic capacities of the victim or is simply behaving as though they do for other reasons. This also means that the focus of epistemic injustice is placed less on the perpetrator, and more on the victim.

The new account avoids the pitfalls of both the enumerative method, and of the pluralist method. It avoids inelegance, as it utilizes broader terms, and does not require or result in an ever-expanding list of kinds of epistemic injustice, or accounts of epistemic injustice. It avoids arbitrariness, as there is a clear set of necessary and sufficient conditions for something being an epistemic injustice. It does not inherit the problems with the Frickerian account, as while it utilizes some of the key concepts, it assigns meanings to those concepts, eliminates problematic concepts, and adds in new useful ones. Finally, it does not result in a paradoxical understanding of epistemic injustice, as only one account of epistemic injustice is being put forward. 


\section{Conclusion}

While epistemic injustice is a popular new topic in philosophy, we have had a poor understanding of the concept of epistemic injustice itself. The Frickerian account, while highly influential and central to the literature on epistemic injustice, fails to provide a satisfactory account of epistemic injustice, as it is ambiguous, in that it fails to clearly define the key concepts involved; incomplete, in that it does not provide a clear set of necessary and sufficient conditions for something being an epistemic injustice; and it is not practically useful, in that it does not allow us to recognize epistemic injustices in many real-life situations, as it requires that we have access to more information than we are likely to have.

The literature beyond the Frickerian account does not overcome these problems. Neither the enumerative or the pluralist methods of progressing the idea of epistemic injustice solve the problems with the Frickerian account, and each come with their own problems. The enumerative method is inelegant, in that it results in a long list of different kinds of epistemic injustice, and arbitrary, as it is being formed without a clear set of necessary and sufficient requirements for epistemic injustice in place. The pluralist method is also inelegant, as it results in there being many different accounts of epistemic injustice, and risks being paradoxical, with multiple, potentially conflicting accounts of epistemic injustice being utilized.

A new account of epistemic injustice was therefore needed, which in this thesis I have aimed to provide. This account is built on the key concepts of the Frickerian account, so as to avoid taking the term "epistemic injustice" and applying it to something entirely different, but aims to clarify and restructure these concepts so that we come to have a clear, philosophically satisfying and practically useful account of epistemic injustice. The new account of epistemic injustice is as follows: epistemic injustice occurs when someone is insulted and/or undermined in their capacities as a knower, in an epistemic context, where the perpetrator of the injustice is ethically culpable for the injustice. One's capacities as a knower are to give knowledge, to receive knowledge, to possess knowledge, and to generate knowledge. One is insulted in these capacities if one is not 
recognized or respected in their fulfilling of, or ability to fulfil, one or more of these capacities. One is undermined in these capacities if one is prevented from, or made to face unfair difficulty in, fulfilling one or more of these capacities. An epistemic context is a context in which someone being viewed or treated (or wrongfully not viewed or not treated) as a knower is relevant to the situation. A perpetrator is ethically culpable for the insulting or undermining of someone in their capacity as a knower if the perpetrator insults or undermines them by doing something ethically problematic for which they are responsible, as opposed to making an innocent mistake. 


\section{References}

Abramson, K. (2014). Turning up the lights on gaslighting. Philosophical Perspectives, 28(1), 1-30.

Anderson, D. (2017). Conceptual competence injustice. Social Epistemology, 31(2), (210223).

Bondy, P. (2010). Argumentative injustice. Informal Logic, 3o(3), 263-267.

Coady, D. (2017). Epistemic injustice as distributive injustice. In IJ Kidd, J Medina \& G Pohlhaus Jr (Eds.), The Routledge handbook of epistemic injustice (61-68). Oxon: Routledge.

Cruz, M. (2018). Pragmatic competence injustice. Social Epistemology, 32(3), 143-163.

Davis, E. (2016). Typecasts, tokens, and spokespersons: A case for credibility excess as testimonial injustice. Hypatia, 31(3), 485-501.

Dotson, K. (2012). A cautionary tale: On limiting epistemic oppression. Frontiers: A Journal of Women Studies, 33(1), 24-47.

Fricker, M. (1998). Rational authority and social power: Towards a truly social epistemology. Proceedings of the Aristotelian Society, 98(2), 159-177.

Fricker, M. (1999). Epistemic oppression and epistemic privilege. Canadian Journal of Philosophy, 29(supplement), 191-210.

Fricker, M. (2007). Epistemic injustice: Power and the ethics of knowing. Oxford, UK: Oxford University Press

Fricker, M. (2010). Replies to Alcoff, Goldberg and Hookway on epistemic injustice. Episteme, 7(2), 164-178. 
Fricker, M. (2013). Epistemic justice as a condition of political freedom. Synthese, $190(7), 1317-1332$.

Fricker, M. (2017). Evolving concepts of epistemic injustice. In I. J. Kidd, J. Medina, \& G. Pohlhaus Jr. (Eds.), The Routledge handbook of epistemic injustice (53-6o). Abingdon, UK: Routledge.

Hawley, K. (2012). Knowing how and epistemic injustice. In J. Bengson \& M. A. Moffit (Eds.), Knowing how: Essays on knowledge, mind, and action (283-298). Oxford, UK: Oxford University Press.

Luzzi, F. (2016). Testimonial injustice without credibility deficit. Thought: A Journal of Philosophy, 5(3), 203-211.

McKinnon, R. (2016). Epistemic injustice. Philosophy Compass, 11(8), 437-446.

McKinnon, R. (2017). Allies behaving badly. In I.J. Kidd, J. Medina, \& G. Pohlhaus Jr. (Eds.), The Routledge handbook of epistemic injustice (167-174). Abingdon, UK: Routledge.

Munroe, W. (2016). Testimonial injustice and prescriptive credibility deficits. Canadian Journal of Philosophy, 46(6), 924-947.

Peet, A. (2017). Epistemic injustice in utterance interpretation. Synthese, 194(9), 34213443.

Pohlhaus, G. (2017). Varieties of epistemic injustice. In I. J. Kidd, J. Medina, \& G. Pohlhaus Jr. (Eds.), The Routledge handbook of epistemic injustice (13-26). Abingdon, UK: Routledge.

Woolf, V. (1977). A room of one's own. London, UK: Panther Books. 